Portland State University

PDXScholar

6-7-1982

\title{
Acoustical and Perceptual Correlates of Vocal Effort in Normal Hearing and Hearing-Impaired Children
}

Corinne A. Thomas-Kersting

Portland State University

Follow this and additional works at: https://pdxscholar.library.pdx.edu/open_access_etds

Part of the Speech Pathology and Audiology Commons

Let us know how access to this document benefits you.

\section{Recommended Citation}

Thomas-Kersting, Corinne A., "Acoustical and Perceptual Correlates of Vocal Effort in Normal Hearing and Hearing-Impaired Children" (1982). Dissertations and Theses. Paper 3219.

https://doi.org/10.15760/etd.3210

This Thesis is brought to you for free and open access. It has been accepted for inclusion in Dissertations and Theses by an authorized administrator of PDXScholar. Please contact us if we can make this document more accessible: pdxscholar@pdx.edu. 
AN ABSTRACT OF THE THESIS OF Corinne A. Thomas-Kersting for the Master of Science in Speech Communication, with an emphasis in Speech Pathology/Audiology, presented June 7, 1982.

Title: Acoustical and Perceptual Correlates of Vocal Effort in Norma 1 Hearing and Hearing-Impaired Children.

APPROVED BY MEMBERS OF THE THESIS COMMITTEE:

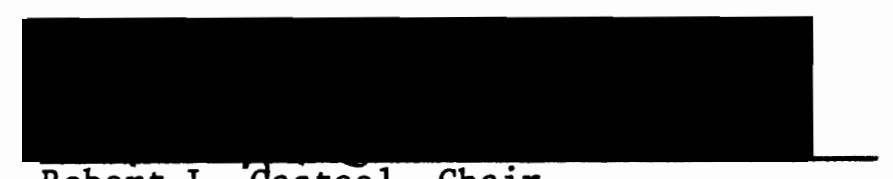

Robert L. Jastee1, Chair
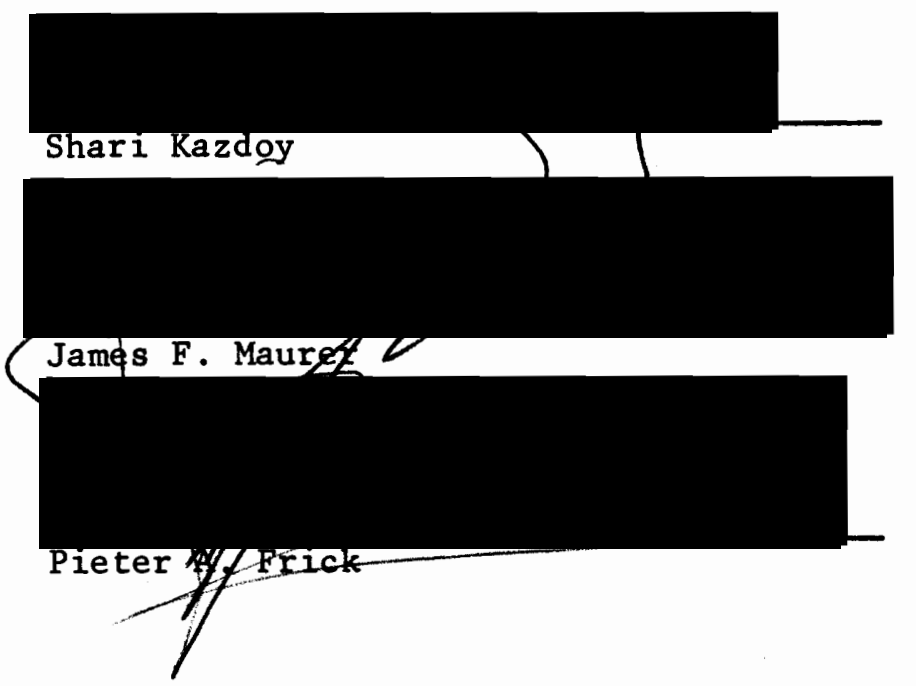

Audition is undoubtedly the most efficient means for early acquisition of oral communication skills (Fry, 1978; Ling, 1976). Consequently, the speech of children with limited audition deviates from normal speech in almost all aspects (Calvert and Silverman, 1975). One problem area is voice quality, specifically vocal effort or harshness. Even though abnormal vocal effort is prevalent among 
hearing-impaired speakers, there is a paucity of information describing the acoustical and perceptual features of this voice quality for hearing-impaired children. Whitehead and Lieberth (1979) explored vocal harshness in hearing-impaired adults and found a significant and systematic increase in the level of inharmonic energy, indexed as spectral noise, as the degree of perceived vocal harshness/tension became more severe. The constraints of the instrument used by Whitehead and Lieberth, however, precluded using children as subjects. To date, no research has been reported that specifically describes vocal effort or harshness in hearing-impaired children. An apparent need, therefore, existed to implement a research design with which hearingimpaired children could comply and that revealed data concerning the perceptual and acoustical features of vocal effort in hearing-impaired children.

The present study was designed to investigate the perceptual and spectrographic features of vocal effort in the speech of severely to profoundly hearing-impaired children and their normal hearing agemates. Recorded vowel and speech samples were obtained from ten normal hearing children, ten severely to profoundly hearing-impaired children attending Oral/Aural educational programs, and eight severely to profoundly hearing-impaired children attending Total Communication programs. The degree of perceived vocal effort for vowels and speech was evaluated, using a nine point equal-appearing-interval scale. In order to obtain a physical measurement for vocal effort, a digital wave analyzer was used to produce vowel spectra, and the amount of inharmonic (noise) components in each spectrum was indexed as spectral 
noise leve1.

The results indicated: 1) there is a positive and significant correlation of moderate strength between spectral noise levels and perceived degrees of vocal effort for samples of hearing-impaired and normal hearing children; 2) hearing-impaired children tend to demonstrate higher vowel spectral noise levels, although this difference was significant only for the vowe $1 / u /$ and not for the vowel $/ a /$; 3) hearing-impaired children are perceived as demonstrating significantly more vocal effort than normal hearing children; 4) Total Communication hearing-impaired students cannot be significantly differentiated from Oral/Aural students in terms of spectral noise levels; and 5) Total Communication students are perceived as demonstrating significantly greater vocal effort than Oral/Aural students for the vowel /u/ and for speech. 
ACOUSTICAL AND PERCEPTUAL CORRELATES OF VOCAL EFFORT

IN NORMAL HEARING AND HEARING-IMPAIRED CHILDREN

by

CORINNE A. THOMAS-KERSTING

A thesis submitted in partial fulfillment of the requirements for the degree of

MASTER OF SCIENCE IN SPEECH COMMUNICATION

with an emphasis in

SPEECH PATHOLOGY/AUDIOLOGY

Portland State University

1982 
TO THE OFFICE OF GRADUATE STUDIES AND RESEARCH:

The members of the Committee approve the thesis of Corinne A. Thomas-Kersting presented June 7, 1982.

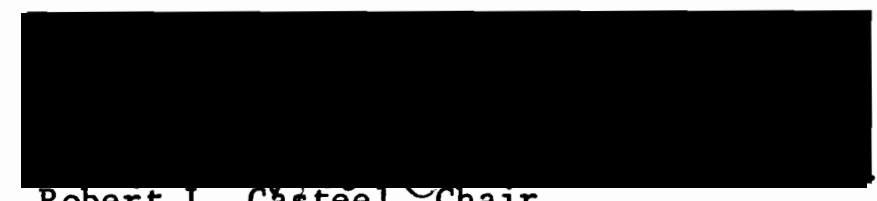

Robert L. Casteel, Chair

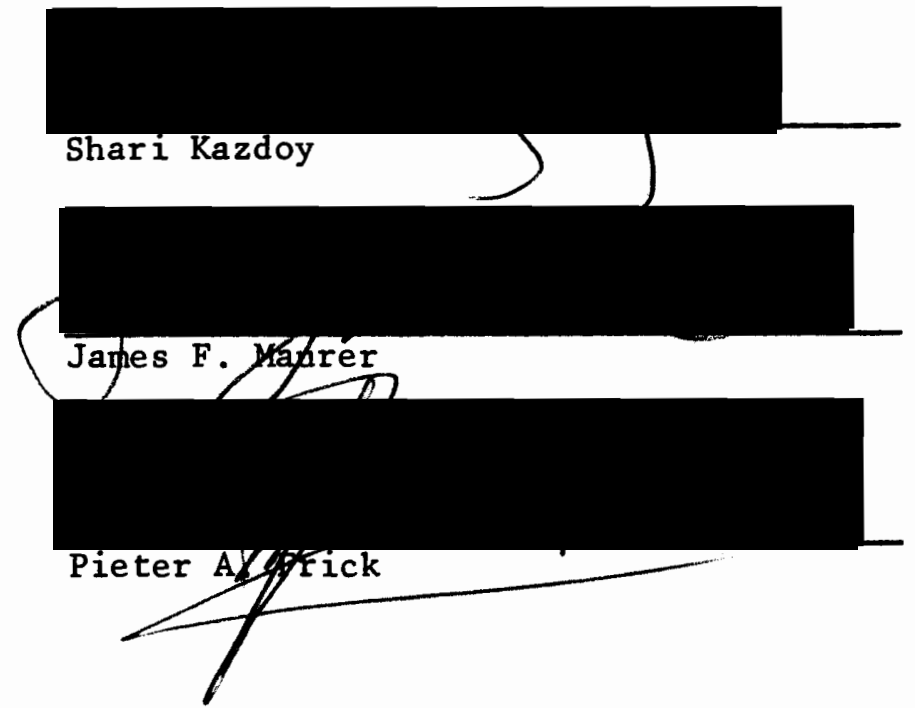

APPROVED :

Theodore G. Grove, Head, Department of

Speech Communication

Stanley E. Rauch, Dean, Graduate Studies

and Research 


\section{ACKNOWLEDGEMENTS}

I feel fortunate to have worked with many warm, creative, and supportive people during this research endeavor. Certainly the most rewarding moments have been spent chatting and problem-solving with some of the most interesting people in the world.

Special thanks to my thesis director, Bob Casteel, for pouring much energy and inspiration my way. You are a good friend.

I am grateful to my thesis committee members, Shari Kazdoy, James Maurer, and Pieter Frick. Each one of you contributed special expertise and support.

Lee Jensen, you are a superb farmer, electrical engineer, and human being. What an impressive combination! I am eternally grateful for the many hours of work you dedicated to this study.

Ralph Coleman, my discussions with you on psychoacoustics were enlightening. I learned so much from you! I also want to express sincere gratitude to Ted Grove for his help with statistics, Al Hicks for his technical advice and assistance with the mobile hearing testing van, and Gordon Frey for his technical assistance with the recording instruments and tape preparation.

My appreciation also extends towards Sue Saling of the Portland Regional Program for the Deaf, Pat Stone of Tucker-Maxon Oral School, and Mr. Wilson of the Salem Regional Program for the Deaf. The collaboration of these professionals and the parents, children, and staff of these three school systems was essential for this study. 
The three perceptual judges for this study were Mary Gordon, Karen Kumpula-Lacey, and Ann Laskey. Thanks, your cooperation and expertise were invaluable.

Finally, my friends and family all deserve a special hug. I felt your encouragement, love, and confidence always. And to my best friend, Felix, I dedicate this thesis. 
TABLE OF CONTENTS

Page

ACKNOWLEDGEMENTS ...................

LIST OF TABLES ..................... vii

LIST OF FIGURES ................... . . viii

CHAPTER

I OVERVIEW AND STATEMENT OF THE PROBLEM . . . . . . 1

Overview of the Problem ............ 1

Articulation, Rate, Loudness, and Rhythm

Characteristics of Hearing-Impaired Speakers

Pitch Characteristics of Hearing-Impaired Speakers

Voice Quality Characteristics of Hearing-

Impaired Speakers

Statement of the Problem .......... 14

II METHODS AND PROCEDURES . . . . . . . . . . . . 16

Methods . . . . . . . . . . . 17

Subjects

Speech Sample

Instrumentation

Procedures ................

Data Collection

Preparation of Tapes

Data Measurement

Statistical Analysis of Data

III RESULTS AND DISCUSSION . . . . . . . . . . 39

Results................ 39 
Discussion ...............

Acoustical Measurement of Vocal Effort

Perceptual Measurement of Vocal Effort

Acoustical and Perceptual Differences

between Normal Hearing and Hearing-

Impaired Children

Acoustical and Perceptual Differences

between Oral/Aural and Total Communication

Students

Summary . . . . . . . . . . . . . . . 69

Implications . . . . . . . . . . . . 71

Clinical Implications

Research Implications

BIBLIOGRAPHY . . . . . . . . . . . . . . . 75

APPENDICES ....................... 80

A PARENT PERMISSION SLIP . . . . . . . . . . . 81

B PARENT PERMISSION SLIP . . . . . . . . . . 82

C INSTRUCTIONS FOR ELICITING /ba/ AND /bu/ .... 83

D SELECTED EXAMPLES OF VOWEL SPECTRA PRODUCED

BY THE HEWLETT PACKARD WAVE ANALYZER . . . . . . . 85

E INSTRUCTIONS TO JUDGES - VOCAL EFFORT RATING;

PART I: TRAINING SESSION FOR VOWELS . . . . . . 94

F INSTRUCTIONS TO JUDGES-VOCAL EFFORT RATING;

PART II： VOWEL JUDGEMENTS . . . . . . . . 97

$G$ INSTRUCTIONS TO JUDGES-VOCAL EFFORT; PART III:

TRAINING AND JUDGEMENT OF SPEECH SAMPLES . . . . . 98

H GUIDELINES FOR PERCEPTUAL JUDGEMENT: VOCAL EFFORT • . 100 


\section{LIST OF TABLES}

TABLE

Page

I Inter-Judge Reliability for /a/ Ratings . . . . . . 34

II Inter-Judge Reliability for /u/ Ratings . . . . . . . 34

III Inter-Judge Reliability for Speech Ratings . . . . . . . 35

IV Canonical Correlations for Ratings of Pairs of Judges . . . . . . . . . . . . . . 36

V Correlation Coefficients for Vowel Ratings and Vowel Spectral Noise Levels . . . . . . . . . 40

VI Correlation Coefficients for Speech Ratings and Vowel Spectral Noise Levels . . . . . . . . . . 44

VII Comparison of Spectral Noise Levels for Normal Hearing and Hearing-Impaired Children . . . . . . . 48

VIII Comparison of Perceptual Ratings for Normal Hearing and Hearing-Impaired Children . . . . . . . . . 49

IX Comparison of Spectral Noise Levels for Oral/Aural and Total Communication Students... . . . . . 51

$X$ Comparison of Perceptual Ratings for Oral/Aural and Total Communication Students . . . . . . . . . 
LIST OF FIGURES

1 Hewlett Packard Spectrum Analyzer (HP 3582A) . . . . . 21

2 General Radio Wave Analyzer (Type 1910-A) . . . . . . 23

3 Mean spectral noise levels and mean vocal effort ratings for the vowel / $a /$ produced by 10 normal hearing children, 10 Oral/Aural hearing-impaired children, and 8 Total Communication hearingimpaired children . . . . . . . . . . . . .

4 Mean spectral noise levels and mean vocal effort ratings for the vowe $1 / \mathrm{u} /$ produced by 10 normal children, 10 Oral/Aural hearing-impaired children, and 8 Total Communication hearingimpaired children . . . . . . . . . . . . . .

5 Spectral noise level means and standard deviations for the vowels / $\mathrm{a} /$ and $/ \mathrm{u} /$. produced by 10 normal hearing and 18 hearing-impaired children . . . . .

6 Means and standard deviations for perceived vocal effort ratings for the vowe $1 \mathrm{~s} / a /$ and $/ u /$ and speech produced by 10 normal hearing and 18 hearing-impaired children . . . . . . . . . . .

7 Spectral noise level means and standard deviations for the vowe $1 \mathrm{~s} / \mathrm{a} /$ and $/ \mathrm{u} /$ produced by 10 Oral/Aural and 8 Total Communication hearingimpaired children . . . . . . . . . . . . . .

8 Means and standard deviations for perceived vocal effort ratings for the vowels /a/ and /u/ and speech produced by 10 Oral/Aural and 8 Total Communication hearing-impaired children . . . . . . 


\section{CHAPTER I}

OVERVIEW AND STATEMENT OF THE PROBLEM

OVERVIEW OF THE PROBLEM

Feedback through auditory sensation is undoubtedly the most important and efficient means for the early acquisition of oral commnication skills (Fry, 1978; Ling, 1976). The child who receives distorted and weak auditory messages is not able to develop the auditory feedback mechanisms necessary for spontaneous development of speech. In other,words, the child with impaired audition is severely disadvantaged in learning to properly coordinate the speech mechanism. It follows that the speech of hearing-impaired persons deviates from normal speech in almost all aspects, including articulation, rate, loudness, rhythm, pitch, and vocal quality (Calvert and Silverman, 1975).

Articulation, Rate, Loudness, and Rhythm Characteristics of Hearing-Impaired Speakers

Speech intelligibility of hearing-impaired speakers is documented as being poor. According to Ling (1976), the naive listener can usually only understand between 20 and 30 percent of what the severely to profoundly hearing-impaired child says. Misarticulations resulting from incoordination of the speech mechanism contribute to this low intelligibility (Parkhurst and Levitt, 1978). Several authors allude to the neutralization of vowels, a product of stereo- 
typed tongue movement, as a predominant speech error pattern (Angelocci, Kopp, and Holbrook, 1964; Hudgins and Numbers, 1942 ; Markides, 1970). Markides also reported that about 72 percent of the consonants produced by severely to profoundly hearing-impaired children are misarticulated. Consonantal errors include voice-voiceless confusions, substitutions, omissions, and distortions (Hudgins and Numbers, 1942; Nickerson, 1975; Penn, 1955) with the greatest number of errors occurring with the least visible sounds (Nober, 1967).

Descriptions of deaf speech traditionally include aberrant rate patterns. Penn (1955) found about half of the adult male hearingimpaired subjects participating in his study talked too rapidly, too slowly, in a monotone, or staccato. Other researchers (Hood and Dixon, 1969; Hudgins and Numbers, 1942; Markides, 1970; Mason and Bright, 1937; Monsen, 1979) found that hearing-impaired individuals may prolong syllables and typically produce slow and labored speech. Limited published data are available describing the loudness problems associated with impaired audition. Martony (1968) observed abnorma11y large intensity variations in hearing-impaired subjects. Penn (1955) contends that the speaking volumes of hearing-impaired persons may depend upon the nature of their impairment. Speakers with conductive losses tend to speak abnormally soft, while persons with sensorineural losses tend to speak unusually loud. Penn explains this occurs because a person with a conductive 1088 may hear her own voice via bone conduction, while a person suffering from sensorineural loss of audition does not receive bone conducted feedback.

Speech rhythm is often called the "melody' (Nicolosi, Harryman, 
and Kresheck, 1978) of speech and includes aspects of duration, fundamental frequency variation (intonation), and intensity variation. As a composite of all the speech parameters, speech rhythm is frequently described as the predominant abnormal feature of deaf speech (Calvert and Silverman, 1975). Hood and Dixon (1969) found that the aberrant durational aspects of speech probably most influence the perception of deviant speech rhythm for hearing-impaired speakers. These authors and Hudgins and Numbers (1942) agree that speech rhythm proficiency is strongly related to intelligibility of hearing-impaired speakers.

\section{Pitch Characteristics of Hearing-Impaired Speakers}

Substantial research has described the pitch patterns which typify the speech of the auditorily handicapped. One of the most researched parameters of deaf speech is habitual pitch or fundamental frequency. McGarr and Osberger (1978) and Nickerson (1975) observed that the speech of hearing-impaired persons is often characterized by a pitch too high or too low for the sex and age. Angelocci et al. (1964) found that the mean fundamental frequency of eleven to fourteen year old profoundly hearing-impaired boys was significantly higher than for normal hearing boys. Boone (1966) replicated this finding in seventeen to eighteen year old hearing-impaired boys. He found, however, no statistically significant deviation from normal for adolescent girls or seven to eight year old children with auditory impairments. Boone concluded that use of an inappropriately high voice tended to be more 1 imited to male adolescents and adults.

Monsen (1979) investigated the average fundamental frequency of hearing-impaired three to six year olds and found this value to be 
slightly above normal but within an acceptable range. Monsen's findings would seem to further document Boone's (1966) assertion that younger hearing-impaired children generally do not demonstrate habitual pitches outside the range of normal. Even though Monsen did not find significantly different fundamental frequencies, he did find that the young hearing-impaired children who demonstrated lower fundamental frequencies were perceived as exhibiting significantly better voice qualities. The correlation coefficient between mean fundamental frequency and voice quality ratings was -0.52 .

Monsen (1979) also looked at fundamental frequency changes that occurred over time during an utterance. He found that fundamental frequency contours, or pitch change patterns, were important relative to the perceived voice quality of young hearing-impaired subjects. He identified several types of fundamental frequency contours demonstrated by the three to six year olds with impaired audition. The normal pitch change pattern was characterized by a regular decline of the fundamental frequency at a rate less than $10 \mathrm{Hertz}$ per $100 \mathrm{msec}$ for the duration of the utterance. Aberrant fundamental frequency contours included rapid and dramatic changes in pitch, random-1ike pitch variations, and limited variations in pitch (monotone). Monsen found a positive correlation between the hearing-impaired subjects' amount of deviation from the normal fundamental frequency contour and the perception of abnormal voice quality. The correlation coefficient between perceived voice quality ratings and scores based upon quantification of the fundamental frequency contours was +.88 . This led Monsen to conclude that variations of frequency within an utterance 
seem to be the most important factor differentiating better from poorer voice quality. He hypothesized that the abnormal variation in pitch is probably due to poor control of air supply and vocal fold tension. Monsen stressed that it is paramount that the vocal mechanism is not tense for speech production.

Aberrant pitch variation was also documented by Angelocci et al. (1964). These authors found that fundamental frequency varied more from vowel to vowel for the speakers with impaired auditory acuity. While this rate of vibration at the level of the vocal folds varied more dramatically from vowel to vowel, the first and second formants, determined by the shape and size of the resonating cavities, varied less. Angelocci and his colleagues concluded that the hearingimpaired speaker attempts to change the acoustical characteristics of vowels by varying the rate and amplitude of vocal fold vibration, rather than the frequency and amplitude of formants. In other words, the speaker is differentiating vowels by excessive laryngeal variations rather than appropriately varying resonant characteristics. Martony (1968) observed patterns in which the hearing-impaired speaker tended to use abnormally high pitches at the beginning of a breath phrase, followed by a gradual drop to a more natural level. Furthermore, Willemain and Lee (1971) found that many hearing-impaired individuals raise their habitual pitch when they speak more complex utterances. In the investigation each subject repeated her name at a higher frequency than humming and read aloud at an even higher pitch. These authors concluded that the unnatural pitch patterns may be a product of the hearing-impaired speaker's attempt to increase internal 
feedback during voicing. They speculated that by increasing the tension in the cricothyroid muscle and by increasing subglottic air pressure, the speaker provides greater opportunity for kinesthetic awareness in the absence of sufficient auditory feedback. The authors also advanced an alternate or compounding speculation that the hearingimpaired speaker may be bringing generalized inappropriate tension to more difficult communicative tasks.

In summary, the pitch characteristics of hearing-impaired speakers include aberrant fundamental frequency and erratic, excessive, or limited variation of fundamental frequency during an utterance. Several authors (Monsen, 1979; Willemain and Lee, 1971) speculated that the deviant pitch patterns may be associated with inappropriate muscular tension during speaking. Additionally, Monsen found moderate and high correlations between subjects' perceived voice quality and their pitch and fundamental frequency contours, respectively. Since pitch variations are known to result from laryngeal adjustments (Zemlin, 1968), it follows that investigations involving pitch may interface with voice quality research.

\section{Voice Quality Characteristics of Hearing-Impaired Speakers}

The vocal characteristics of severely to profoundly hearingimpaired speakers have been described in numerous ways. According to Calvert and Silverman (1975), adjectives used to describe deaf voices include "dul1," "raspy," "piercing," "tense," "harsh," "throaty," and "shrieking." It has been the experience of these authors that terms such as "mellow," "warm," "full," or "clear" are never mentioned when describing this population's voice quality. Unfortunately, these 
adjectives are not clearly defined and, therefore, there is ambiguity in the literature when describing the speech of hearing-impaired persons. Confounding the problem is the fact that there are little objective data available regarding the acoustic correlates of abnormal voice, especially in the hearing-impaired population. Quantitative measures for identifying and assessing the severity of voice disorders are limited and normative data are lacking.

Several authors have addressed the aberrant resonant characteristics of the auditorily impaired speaker's voice. Boone (1966) noted that the tongue tends to be held too far back toward the pharyngeal wall by hearing-impaired speakers. He described the resulting voice quality as being characterized by a "pharyngeal focus of resonance." Boone also contends that the posterior retraction of the tongue resulting in pharyngeal resonance is often accompanied by another resonance disorder: denasality. Other researchers (Colton and Coorer, 1968; Fletcher and Daly, 1976; Hudgins and Numbers, 1942; Stevens, Nickerson, Boothroyd, and Rollins, 1976) have identified excessive nasal resonance as a characteristic common to the speaker with impaired hearing. Whether the hearing-impaired speaker demonstrates hypernasality, hyponasality, or pharyngeal focus of resonance, control of the velum and tongue has long been recognized as a source of difficulty and is indicative of the general lack of coordination among the speech mechanisms (Gilbert and Campbe11, 1978; Nickerson, 1975).

Recently, the improper control of the larynx has received attention. Monsen (1979) and Monsen, Engebretson, and Vemula (1979) measured the successive period-to-period changes in frequency and ampli- 
tude (jitter and shimmer) in order to examine the effects of hearing impairment on the generation of voice. Excessive jitter, as measured by significant variations in adjacent periods, has been related to laryngeal dysfunction (Michel and Wendah1, 1971). Shimer has been described as a physical correlate to measure roughness or hoarseness (Horii, 1980). Monsen found no excessive period-to-period variation in fundamental frequency or intensity which could differentiate three to six year olds with auditory impairments. In another study, however, Monsen et al. found discernible differences between the degree of jitter and shimmer in hearing-impaired and normal hearing adolescents. Additionally, these authors noted the abnormal occurrence of "vocal fry" at the onset or middle of some phonatory samples of the hearing-impaired subjects. Based upon their observations, Monsen et al. concluded that the hearing-impaired speaker does not properly control the overall tension of his vocal folds or subglottic air pressure in the same way as the normal hearing speaker does.

Forner and Hixon (1977) agree that the hearing-impaired speakers exhibit poor control of the speech apparatus. They describe that the degree of subglottic air pressure and the "resistive mechanical load of the larynx," influenced by muscular tension, are adversely affected in hearing-impaired speakers. Some subjects in this study exhibited extreme air flow resistance accompanied by harsh vocal qualities. Other subjects, however, exhibited low laryngeal resistance to the flow of air and breathy voice qualities. Inappropriate degrees of laryngeal tension (either too tense or too lax) were responsible for producing these aberrant voice qualities, harsh and breathy. 
Of all the voice quality descriptors, "harshness" is perhaps the most elusive term. "Harsh" voice is used interchangeably in the literature with "rough," "hoarse," "husky," "strident" (Isshiki, Yanagihara, and Morimoto, 1966), and "tense" (Whitehead and Lieberth, 1979). Spector, Subtelny, Whitehead, and Wirz (1979) report that the incidence of vocal hypertension and harshness is relatively high in the hearing-impaired population. In a survey of students entering the National Technical Institute for the Deaf (NTID), 11 percent were identified as demonstrating excessively harsh or tense sounding voices. Even though vocal harshness is prevalent among hearing-impaired speakers, there is a paucity of information about the acoustic features of harsh voice production for this population. Whitehead and Lieberth (1979) have published one of few studies exploring vocal harshness in hearing-impaired speakers. Twenty male NTID students, nineteen to twenty-four years of age with profound hearing losses, participated in this study. The subjects sustained two vowels (/a/ and $/ u /$ ) and read two sentences. Perceptual and spectrographic analyses were made of recordings of this material. Three judges rated the vowe ls and sentences for degree of vocal harshness, using a 5-point equal-appearing-interval scale. This perceptual scale ranged from "normal phonation" to "tension too severe to sustain phonation." Spectrographic analysis was accomplished by measuring inharmonic (noise) components in the acoustic spectrum. A frequency-by-amplitude acoustic spectrum was plotted for each vowel production, using a General Radio Wave Analyzer (Model 1523-P4) in its 10 Hertz bandwidth mode. The amount of inharmonic components in the vowel spectra was 
quantified by indexing spectral noise levels. For the purposes of Whitehead and Lieberth's study, spectral noise levels were measured as the "lowest observable peak in the graphic level recording . . measured in dBSPL in successive 100 Hertz spectral segments in the frequency range 100-3000 Hertz."

The procedures used by whitehead and Lieberth (1979) to compare perceptual and acoustical features of vocal harshness were previously described by Lively and Emanual (1970) and Sansone and Emanual (1970). These authors conducted studies in which non-handicapped men and women sustained five vowels first normally and then with simulated roughness. Each vowel production was rated, using a 5-point scale for vocal "roughness," and also was subjected to spectrographic analysis. A 3 Hertz bandwidth frequency-by-amplitude acoustic spectrum was plotted for each vowel, using a General Radio Wave Analyzer (Model 1910-A). Spectral noise levels were indexed as the "lowest observable level-recording stylus marking in each 100 Hertz segment of the spectrum." Multiple coefficients indicated that the relationships between perceived "roughness" and measures of spectral noise in the range of 100 Hertz to 2600 Hertz were high $(>+.90)$ and significant for all vowels. Lively/Emanual and Sansone/Emanual also found that harmonic components tended to diminish in amplitude with an increase in spectral noise levels (or inharmonic energy levels) for vowels. These findings were consistent with Isshiki, Yanagihara, and Morimoto's (1966) observations that spectral noise components are higher during the production of "hoarse" voice. Isshiki et al. based their conclusions upon visual inspection and comparison of normal and "hoarse" vowel spectro- 
graphs. Lively/Emanual and Sansone/Emanual's research marked the first time that spectral noise levels were numerically quantified following the above described method.

When Whitehead and Lieberth (1979) applied Lively and Emanual (1970) and Sansone and Emanual's (1970) methodology to hearingimpaired subjects, they also found a significant and systematic increase in spectral noise levels as the degree of perceived vocal harshness for vowels and running speech became more severe. Whitehead and Lieberth reported correlation coefficients $\mathbf{Z}-.84$ when comparing vowel spectral noise to vowel ratings; coefficients comparing vowel spectral noise to speech ratings were $\geq-.60$. For their analysis, Whitehead and Lieberth reversed the order of the perceptual rating scale values; thus these negative correlations reflect the identical type of relationship as reported by Lively/Emanual and Sansone/ Emanual. In other words, the profoundly hearing-impaired subjects who sounded more harsh also generally produced vowel spectra which exhibited larger amounts of inharmonic components and reduced harmonic energies.

Whitehead and Lieberth (1979) concluded from their study that measures of vowel spectral noise levels may provide a useful clinical tool to evaluate the degree of vocal harshness or tension in the profoundly hearing-impaired population. These authors used the terms "tense" and "harsh" synonymously on the basis that harshness is a voice quality associated with excessive tension. This association between harshness and tension was suggested by the results of another publication based upon NTID research of the effects of a relaxation 
program (Spector et al., 1979). Reportedly, the NTID relaxation program successfully achieved reduced perceived vocal tension/harshness in adult deaf speakers.

The most recent product of NTID research on vocal harshness in hearing-impaired adults is an article by Wirz, Subtelny, and Whitehead (1981). In this study, the perceptual and spectrographic features of the speech of deaf adults was assessed pre- and post-therapy designed to reduce vocal tension. Perceptual judgements included subjective ratings of vocal tension/harshness, pitch register, and pitch control. Acoustical analysis included determination of the fundamental frequency and quantification of the spectral energy levels between 500 and 8000 Hertz. Spectral energy levels were measured differently than in the previous study; sonographic amplitude sections were made for each steady-state vowel and the maximum amplitude within each 1000 cycle band was quantified. Wirz, Subtelny, and Whitehead reported that a significant reduction of perceived tension/harshness was achieved post-therapy. Additionally, phonations perceived as less tense, posttherapy, were characterized by lower energy levels between 500 and 8000 Hertz. These authors also reported significant relationships between ratings of pitch register, measures of fundamental frequency, and severities of vocal tension/harshness in deaf adults. These authors hypothesized that the reported aberrant pitch and voice characteristics were products of the same phenomenon: increased muscular tension in the larynx.

These two studies (Whitehead and Lieberth, 1979; Wirz et al., 1981) represent the only published contributions to date which address 
vocal harshness in hearing-impaired speakers and attempt to quantify the psychoacoustical and physical characteristics of this voice disorder. A major limitation of this available data has been the restricted ages of participating subjects. Both studies used students at the NTID who were nineteen years plus. To this date, no statement has been made concerning the spectrographic and perceptual features of harshness in hearing-impaired children. One reason for this may be the constraints of the instrument previously used. In the NTID studies cited, the research design required that subjects maintain a stable intensity level for a five-second duration at constant intensity (75 dBSPL $\pm 1 d B$ ). The General Radio Wave Analyzer used by whitehead and Lieberth required this duration of steady-state vowel for valid measurements of spectral noise levels. This requirement places difficult demands upon speakers with limited audition.

While whitehead and Lieberth (1979) and Wirz et al. (1981) reported success in training deaf adults to produce steady-state vowels, it would seem unrealistic to demand hearing-impaired children to sustain vowels for five seconds at a constant and predetermined intensity level.

There exists a need to implement a research design that hearingimpaired children can comply with and that reveals data concerning the perceptual and spectrographic features of vocal harshness in hearingimpaired children. If psychoacoustical and physical instruments are available that reliably assess hearing-impaired children's harshness severity, these tools may prove clinically useful in diagnosis and in monitoring improvement. Additionally, information comparing hearing- 
impaired children participating in different educational programs would be useful.

For the purpose of this study, the term "vocal effort" was used to describe those perceptual characteristics associated with vocal tension, roughness, hoarseness, and/or harshness. This more global term was used to encourage attention to both components of voice quality: the generation of voice at the larynx and resonation in the vocal tract (Michel and Wendah1, 1971). Nicolosi et a1. (1978) described vocal effort as synonymous with vocal harshness, stating this voice quality was the "perceived degree of labor" associated with pitch and intensity problems, overadduction of the vocal folds, and aberrant resonance characteristics resulting from tongue retraction or pharyngeal constriction. Based upon observations of hearing-impaired speakers during production of speech characterized by vocal effort, this author included oral cavity tension to the above aberrant characteristics which may result in vocal effort.

\section{STATEMENT OF THE PROBLEM}

The purpose of this study was to investigate the perceptual and spectrographic features of vocal effort in the speech of severely to profoundly hearing-impaired children and their normal hearing agemates.

The essential questions were:

1. What is the nature of the association, if any, between the measures of spectral noise and perceived degrees of vocal effort for samples of hearingimpaired and normal hearing children? 
2. Is a heterogeneous sample of hearing-impaired children different in spectral noise levels from normal hearing children?

3. Is a heterogeneous sample of hearing-impaired children different in perceived vocal effort from normal hearing children?

4. Are hearing-impaired students attending a Total Communication educational program different in spectral noise levels from Oral/Aural hearingimpaired students?

5. Are hearing-impaired students attending a Total Communication educational program different in perceived vocal effort from Oral/Aural hearingimpaired students? 


\section{CHAPTER II}

\section{METHODS AND PROCEDURES}

This study was designed to investigate the acoustical and perceptual correlates of vocal harshness in normal hearing and severely to profoundly hearing-impaired children. The hearing-impaired children participating in this study attended either Total Communication or Oral/Aural deaf educational programs. Each subject sustained the vowels $/ a /$ and $/ u /$ at a comfortable and stable intensity level. Additionally, these children named twenty common picture cards at a comfortable loudness level. Magnetic tape recordings were made of each vowel production and speech sample. These recordings were played to a panel of three judges who rated the vowels and speech samples for vocal effort, using a 9-point equal-appearing-interval scale. In addition to these perceptual judgements, acoustical analyses of the noise components within the vowel spectra were performed. Recordings of each vowel were equalized in intensity and individually analyzed to produce frequency-by-amplitude spectra. As an index of vowel spectral noise, the lowest peak of energy in each of twenty-four successive 100-Hertz sections from 100 to 2500 Hertz was measured in each vowel spectrum. 
METHODS

\section{Subjects}

Twenty hearing-impaired children, ages seven through eleven, with a pure-tone hearing loss in the better ear of $71 \mathrm{dBHL}$ or greater, served as subjects in this study. Goodman's (1965) classification system was used to facilitate identification of children with a severe to profound hearing loss. This system is probably the most widely recognized among audiologists (Katz, 1978) and defines a severe to profound hearing loss as occurring when the average pure-tone threshold for three discrete frequencies $(500,1000,2000$ Hertz) is equal to or greater than $71 \mathrm{dBHL}$ (re: 1969 ANSI).

The hearing-impaired children's auditory handicaps were considered congenital in nature or of an unknown etiology identified prior to two years of age. These children had no other significant handicaps, such as cerebral palsy. Ten of the hearing-impaired children participated in Oral/Aural programs where speech, reading, writing, and oral communication skills are assisted by speechreading and auditory amplification and training. Eight of the hearing-impaired children participated in Total Communication educational programs. In Total Communication schools, the child receives input through a manual sign language system and fingerspelling, in addition to speechreading, audition, and reading. The Total Communication student is taught to express herself in signs and fingerspelling, as well as speech and writing (Caccamise and Drury, 1976). The mean unaided hearing threshold level for the Oral/Aural students was $92 \mathrm{dBHL}$ for the better ear; the mean unaided hearing threshold level for the Total Communication 
students was $104 \mathrm{dBHL}$ for the better ear.

In order to obtain a reasonable number of subjects, all eligible children enrolled in Total Communication classrooms sponsored by the Portland Regional Program for the Deaf participated in this study. Additiona1ly, two Total Communication students were randomly selected from the Salem Regional Program for the Deaf to serve as subjects. Through the assistance of the principal of a private Oral/Aural school for the deaf and the director of the Portland Regional Program for the Deaf, ten Oral/Aural hearing-impaired subjects were matched to the Total Communication subjects, simply on the basis of age. The mean age of the Total Communication subjects was 117 months with a median age of 124.5 months. The mean age of the Oral/Aural subjects was 116 months, with a median age of 122.5 months. Signed parent permission was obtained from each subject (see Appendix A).

Ten normal hearing six through eleven year olds also participated in this study. These non-handicapped subjects passed pure-tone audiometric screening and attended a Portland Public School. Signed parent permission slips (see Appendix B) were obtained from a larger sample of children within the school. These children were grouped according to ages which matched the Total Communication subjects. Selection was made from these age brackets. The mean age of the normal hearing subjects was 113 months, with a median age of 120 months.

\section{Speech Sample}

In order to obtain a sample for spectrographic and perceptual analysis, subjects individually produced the consonant-vowel syllables /ba/ and /bu/. The subjects sustained the vowel portions of these 
syllables for approximately one second at a comfortable and constant intensity level. The consonant /b/ was selected to precede all vowel productions in order to provide a uniform phonemic environment for the vowels and because this phoneme is visible and relatively easy to produce for the hearing-impaired child.

Additionally, for perceptual assessment only, the subjects named twenty common picture cards selected from the Peabody Articulation Decks. The utterances elicited from these picture cards contained equal representations of the cardinal vowels $/ u /, / i /, / a /$, and $/$ ae/. This artifact was controlled because previous studies have suggested that the degree of perceived harshness varies with the vowel being produced (Sherman and Linke, 1952). Picture card naming was chosen as the format for deriving a speech sample for this study in order to minimize the availability of prosodic cues in the sample.

\section{Instrumentation}

Instrumentation used in this data collection included an audiometer, a device for the subjects to monitor intensity level, an audio recording system, two wave analyzing systems, and a playback system.

Audiometer. A Grason-Stadler audiometer (Model 1701) was used to screen hearing for the ten non-handicapped children.

Intensity Monitoring Device. A V.U. meter with a large $4 \frac{1}{2} "$ face (part of a Berlant series 30 preamplifier and playback device) and an attached dynamic omnidirectional microphone (Electro-Voice, Model 635A) served to provide the subjects with feedback about intensity variation. When the needle on the V.U. meter remained visibly sta- 
tionary, the vowel productions were being sustained at constant intensity. The intensity varied no more than $\pm 0.5 \mathrm{~dB}$, as measured by a digital multimeter (Fluke, Model 80 50A) when the needle on the V.U. meter was visibly stationary.

Audio Recording Device. The audio recording device consisted of a magnetic tape recorder (Ampex, Model 601) used in connection with a dynamic omidirectional microphone (Electro-Voice, Model 635-A) and 3M 176 sound recording tape. The tape recorder had a relatively flat frequency response $( \pm 2 \mathrm{dBSPL})$ from 50 to 2500 Hertz. Frequency response from 2500 Hertz to 10,000 Hertz varied slightly more ( $\pm 3 \mathrm{dBSPL})$. " $\mathrm{A}$ " weighted signal-to-noise ratio was $56 \mathrm{~dB}$ at a tape speed of $7 \frac{1}{2}$ ips.

The Ampex tape recorder also was used in conjunction with a second tape recorder (Sony, Model 777 ) to equalize the intensities of the individually produced vowels prior to spectral and perceptual analysis and the loudness levels of the speech samples prior to listener judgement. Loudness balancing was accomplished by adjusting the intensity level of the signal during a dubbing process involving both tape recorders. The Sony tape recorder (Model 777) had a flat frequency response $( \pm 2 \mathrm{dBSPL})$ from 50 Hertz to 2500 Hertz and $\pm 5 \mathrm{dBSPL}$ from 2500 Hertz to 10,000 Hertz. The "A" weighted signal-to-noise ratio was $56 \mathrm{~dB}$ at $7 \frac{1}{2}$ ips.

Wave Analyzing Systems. A Hewlett Packard Spectrum Analyzer (HP 3582A) (see Figure 1), adjusted for a frequency span of 2500 Hertz, was employed in obtaining a frequency-by-amplitude acoustic spectrum from the recording of each vowel. This corresponded to a 


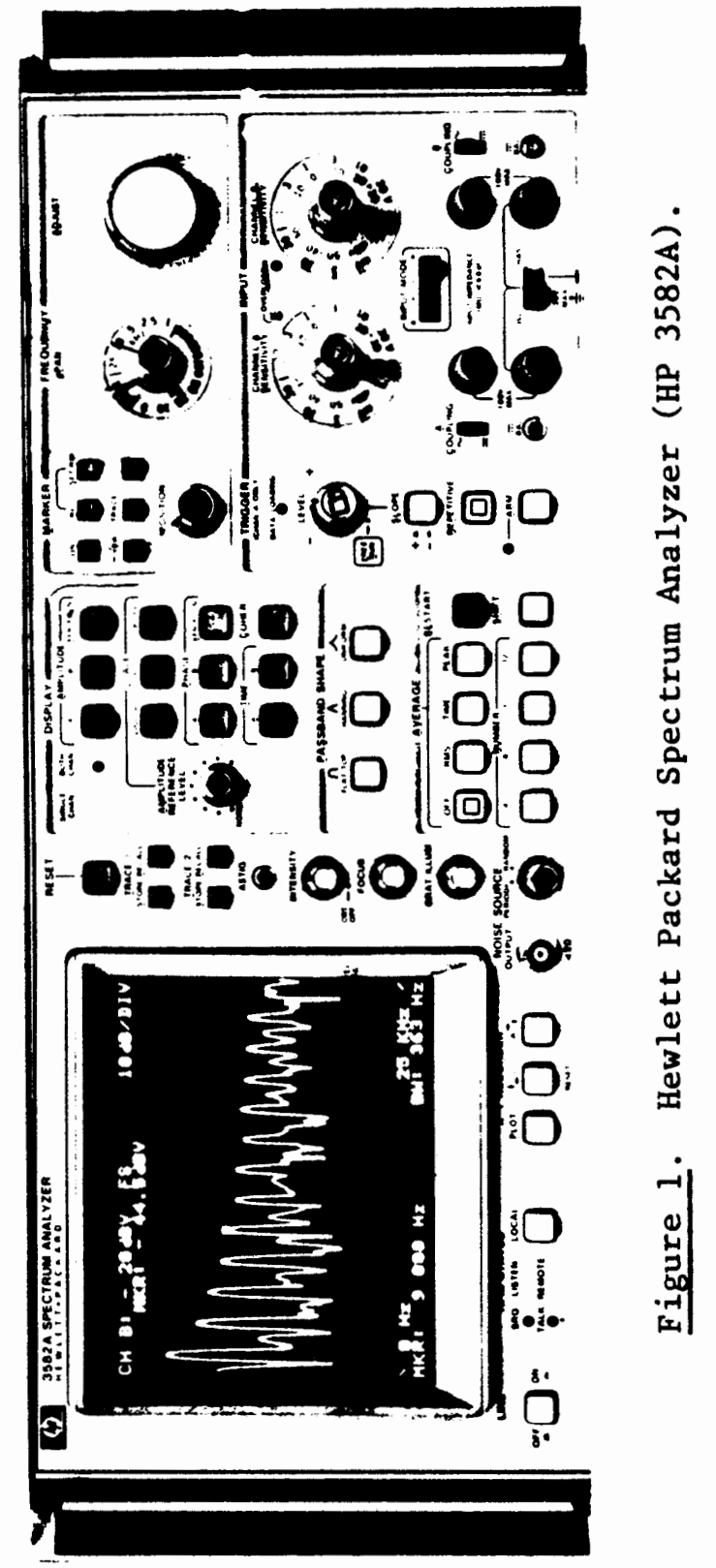


bandwidth of 15 Hertz. Digital spectral analysis took place in approximately $100 \mathrm{msec}$. at this frequency span setting. The analyzer's frequency accuracy to 2500 Hertz was \pm 0.003 percent of center frequency. For this analysis the center frequency was 1250 Hertz and, therefore, the frequency accuracy was \pm 0.0375 Hertz. The Hanning passband was used for this analysis and amplitude accuracy ranged from $\pm 0.5 \mathrm{~dB}$ at the passband center to a maximum of $2.0 \mathrm{~dB}$ uncertainty. This was due to the "picket fence" effect of the Hanning passband filter. Approximately 70 percent of the data points fell within the 1.0 dB amplitude accuracy range.

While performing the spectral analysis, the output from the Ampex tape recorder was first fed into a Hewlett Packard/Harrison amplifier (Model 6824A). Gain on the amplifier was manually adjusted for every vowe 1 in order to equalize the intensity at which each signal was presented to the Hewlett Packard wave analyzer. A small speaker (Radio Shack, Model 40-1227a) and an oscilloscope (Sony/Tektronix, Type 323) provided auditory and visual feedback to the experimenter.

The vowel spectral analysis, consisting of 256 data points, was graphically plotted for ease of inspection, using a digital plotter (Hewlett Packard, Model 7225A). The chart paper was ruled in $10 \mathrm{dBSPL}$ per division vertically and 100-Hertz sections horizontally.

Additional spectral analyses were performed with an analog wave analyzer (General Radio, Type 1910-A) (see Figure 2) used in its 3 Hertz bandwidth mode. The analyzer's frequency accuracy was $\pm \frac{1}{2}$ percent of frequency dial reading plus 5 Hertz. The analyzer's signalto-noise ratio was at least $75 \mathrm{~dB}$. This wave analyzer also was 


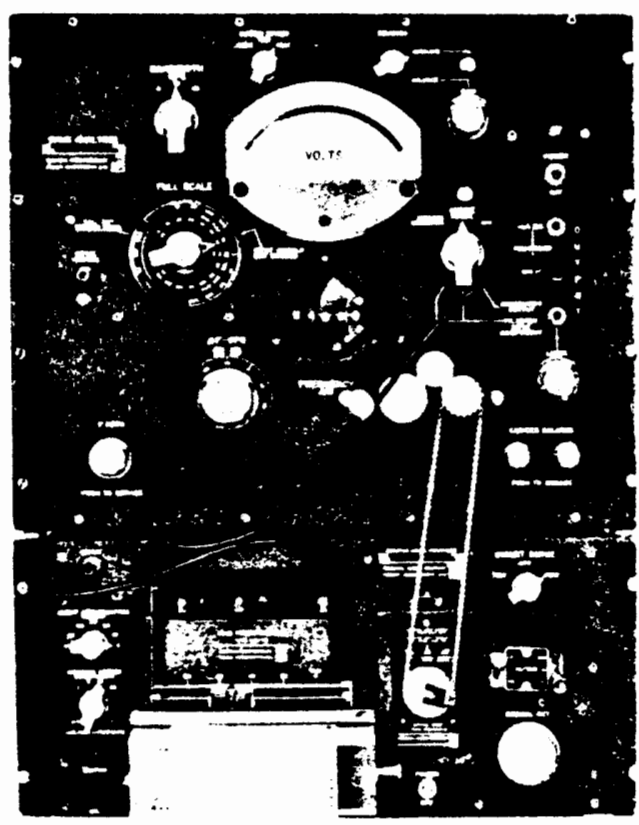

Figure 2. Genera1 Radio Wave Analyzer (Type 1910-A).

equipped with a component graphic level recorder (General Radio, Type 1521-B). The wave analyzer's output voltage, which was proportional to the intensity of the frequency components in the specified bandwidths, was recorded on chart paper ruled in $1 \mathrm{~dB}$ intervals vertically and 100-Hertz sections horizontally.

Playback System. A magnetic tape recorder (Ampex, Model AG 500) with a signa1-to-noise ratio of $40 \mathrm{~dB}$ was used in conjunction with an amplifier and loudspeaker (Ampex, Mode1 622) as the playback system to perceptually evaluate vocal effort.

\section{PROCEDURES}

\section{Data Collection}

Hearing screening was performed prior to data collection to confirm normal hearing sensitivities of the non-handicapped children. 
Hearing screening took place on a mobile hearing testing van, the Auditory Rehabilitation Mobile (ARM). Hearing was screened at 20 dBHL for the frequencies $500,1000,2000,3000,4000$, and 6000 Hertz.

Al1 vowel and speech productions were recorded in acoustically isolated rooms with low ambient noise levels. The hearing testing booths at two schools were utilized for data collection purposes. The ARM van was driven to the two remaining schools for the purpose of gathering this study's data. Each subject's teacher or an assisting adult accompanied the experimenter and the child into the acoustic chamber. The teacher or assistant helped with delivering directions, especially if the child relied heavily upon signs, and helped to monitor the experimental equipment.

Each subject was seated and the recorder microphone was placed at a $70^{\circ}$ angle of incidence to and $6^{\prime \prime}$ in front of the subject's mouth. The microphone attached to the V.U. meter was positioned within $24^{\prime \prime}$ of the subject's mouth, but not necessarily at a uniform distance due to the fact that only relative changes in intensity were being monitored by this system.

The subject was familiarized with the experimental procedure for eliciting sustained vowel productions. Instructions delivered to the subjects are presented in Appendix $C$. The subjects were allowed some preliminary trials with feedback from the experimenter. After the experimenter was satisfied that the subject understood the task, she turned on the tape recorder. The first/ba/ and /bu/ production that met the following criteria was accepted for this study: 1) demonstrating at least one second of constant intensity and 2) subjectively 
matching the perceptual characteristics of that vowel. Training or shaping for each vowel did not continue beyond emission of the first accurately produced vowel, as it was thought that excessive training periods might negatively influence the child's ability to produce her typical voice quality.

After the /ba/ and /bu/ utterances were recorded, the experimenter asked the subject to name some pictures. Twenty picture cards were placed, one at a time, in front of the subject. The subject named these pictures at a comfortable loudness level.

\section{Preparation of Tapes}

Prior to spectrographic and perceptual analysis, the taped vowe 1 and speech samples were prepared for presentation to the wave analyzer and a set of judges. Vowel samples of uniform duration and speech samples consisting of twenty one-word utterances were extracted from the tapes. The vowel and speech samples were randomized and intensity balanced. Additionally, the speech samples were prepared for backward playing.

To extract each vowel sample, a mark was made on the recording tape corresponding to approximately that point where the consonantal portion of the $c-v$ utterance ended. The first $7 \frac{1}{2}$ " of tape occurring after the termination of the initiating plosive was used for the vowel sample. These $7 \frac{1}{2}$ " sections were removed and placed between blank leader tape, utilizing diagonal splicing techniques. In this way, samples of sustained vowels demonstrating uniform durations of one second were prepared for the listeners.

Each speech and vowel sample was assigned a number and, by refer- 
ring to a random number table, arranged in random order. This assigned sequence was adhered to in the tape dubbing which followed. To equalize the intensity levels of the vowels, the recordings were played on the Ampex recorder and dubbed, line-to-1ine, on to magnetic tape on the Sony magnetic tape recorder. During the dubbing process, the V.U. meter was monitored and the line record level dial adjusted so that the signal being recorded was at a uniform intensity, $\pm 1.5 \mathrm{~dB}$ as measured with a digital multimeter (Fluke, Model $8050 \mathrm{~A}$ ).

The loudness levels of the speech samples also were equalized prior to presenting them to a group of listeners. This was done during a dubbing process in a fashion similar to the above procedure for sustained vowels. The reference intensity levels balanced were the maximum loudness levels for each of twenty picture labels. The maximum loudness levels varied $\pm 3.0 \mathrm{~dB}$ for the speech samples. This loudness balancing was performed in order to insure that each utterance was presented to the judges at a sufficient intensity to make vocal quality judgements. Additionally, this procedure eliminated the possibility of distortion resulting from too loud of intensities overdriving the playback system.

The speech samples also were prepared so that they could be presented backwards during the perceptual rating sessions. This was done by recording the speech samples on half-track stereo, both channels, during the dubbing process. During the playback, the positions of the reels on the tape recorder were reversed, thereby changing the direction of the tape as it moved past the playback head. It was thought that backward playing of the speech samples would assist the judges in 
selectively attending to voice quality by reducing the availability of other linguistic cues, such as stress, articulation, and prosody. Sherman (1954) suggested that more valid judgements of vocal harshness severity are made when speech samples are played backwards.

During preparation of the tapes, high frequency instrumentation noise was found on some of the taped samples. The frequency of this interference was above the speech range, at 6000 Hertz or greater. In order to eliminate possible effects of this intermittent high frequency noise upon perceptual judgements of voice, frequencies above 6000 Hertz were attenuated on all tapes, using a Krohn-Hite (Model 3202 R) filter.

\section{Data Measurement}

Two analyses were accomplished on the recorded material. The vowels only were spectrally analyzed and both the vowels and speech samples were evaluated by a panel of judges for vocal effort.

Spectrographic Analysis-Hewlett Packard Wave Analyzer. For this analysis, a tape containing the sustained vowels was played on the Ampex recorder, which was attached to an amplifier and then fed into the wave analyzer. A speaker and an oscilloscope also were attached to the amplifier's output, so that the signal being sent to the wave analyzer could be monitored. The taped vowel samples had previously been dubbed at relatively uniform intensity, $\pm 1.5 \mathrm{~dB}$, as monitored by a V.U. meter. It was thought more precise intensity equalization could be achieved at this time with the aid of an oscilloscope and thus reduce the degree of loudness differences between the vowel samples. The gain on the amplifier was manually adjusted so 
that a uniform maximum deflection of the waveform, as displayed on the oscilloscope, was achieved for each vowel sample. This maximum deflection of the waveform corresponded to the intensity of the signal. The automatic trigger level of the Hewlett Packard wave analyzer was adjusted so that the digital analysis occurred when this uniform intensity was reached. Utilizing this method, the signal amplitudes of the vowels spectrally analyzed varied no more than $\pm 0.2 \mathrm{~dB}$.

After the tracing of the vowe 1 spectrum appeared on the display screen of the Hewlett Packard wave analyzer, the graphic plotter was triggered to print a 15-Hertz bandwidth graphic spectrum of the vowel, consisting of 256 data points (see Appendix D).

The low peak of energy recorded in each 100-Hertz section in the frequency range of 100 Hertz to 2500 Hertz of each vowel spectrum was measured in $\mathrm{dB}$ as an index of spectral noise level. The mean spectral noise level for each vowel sample was calculated by averaging the $d B$ values for the twenty-four 100-Hertz sections. This procedure, which quantifies the degree of inharmonic components, was described by Sansone and Emanual (1970) and Whitehead and Lieberth (1979).

The frequency range of 100 Hertz to 2500 Hertz was selected for analysis because it represented the first two formants of the vowels studied. Spectral noise levels derived from the 100 Hertz to 2600 Hertz frequency range also have been demonstrated to correlate most significantly with the perceived degree of vocal harshness (Sansone and Emanual, 1970). Spectral noise was not measured in the first 100-Hertz segment because ambient and instrumentation noise was known to be greatest in this range. 
To determine the reliability of the wave analyzing technique on successive runs of the same vowel, four vowel spectra were produced from one sustained vowel production for three different samples. The means of the 100-Hertz section spectral noise levels were averaged for 100 Hertz to 2500 Hertz for each of four spectra for these vowels. These mean spectral noise levels did not vary more than $\pm 1.0 \mathrm{~dB}$ across the four spectra. The reliability of the technique for capturing the signal on the wave analyzer was, therefore, considered satisfactory for this study.

The experimenter constructed a template which was used to insure reliable quantification of spectral noise levels from the plotted spectra. The template had verticle lines corresponding to every 100Hertz span, and when overlaid on a printed spectrum, facilitated locating the lowest peak of the pen excursion per 100-Hertz increment. Reliability of this measurement method was assessed by calculating several spectral noise level measurements of the same printed vowel spectrum. The mean spectral noise levels computed for each trial varied no more than $\pm 0.5 \mathrm{~dB}$, indicating the procedure for determining spectral noise levels from the plotted spectra to be satisfactorily reliable.

Spectrographic Analysis-General Radio Wave Analyzer. For comparison purposes, three spectra were replicated using a General Radio wave analyzer (Type 1910-A). Tape loops, approximately two seconds in duration (tape speed $7 \frac{1}{2}$ ips), were constructed by splicing together the duplicate recordings of three of the one-second vowel samples prepared for the Hewlett Packard instrumentation. The three 
tape loops were fed separately into the wave analyzer to produce 3Hertz bandwidth graphic spectral analysis.

Perceptual Ratings. Three judges, consisting of two Portland State University Speech Pathology Clinical Supervisors and one Portland State University graduate student in Speech Pathology, participated in evaluating the vocal effort of each vowel and speech sample. To insure satisfactory inter- and intra-judge reliability, training sessions were conducted prior to the time when any judge listened to the study's recorded data. The training and rating sessions were divided into three tasks. Part I included training for judgements of vocal effort in vowels (see Appendix E); the vowels were rated in Part II (see Appendix F); and finally, training and rating of speech samples occurred in Part III (see Appendix G).

Training materials for vowels consisted of multiple recorded samples of sustained vowels from two normal hearing and five hearingimpaired children. These subjects did not participate in the actual study. A total of twenty-three vowel productions were obtained from these seven children. In addition, vowel productions from four severely to profoundly hearing-impaired subjects who participated in the study were used for the training tape. The vowel samples used from these children were not identical to the samples used for the study. The vowel samples from children belonging to the experimental group were included so that a full spectrum of vocal effort was represented on the training tape.

The twenty-seven recorded vowel samples used for the training tape were prepared by extracting the first one-second segment of 
sustained vowels, randomizing the order of presentation, and equalizing the intensities. The steps used to prepare these training tapes were identical to the procedures used in preparing this study's recorded data.

The judges were trained to rate the vowels, using a 9-point equal-appearing-interval scale. Guidelines for use of this vocal effort scale appear in Appendix H. These guidelines were devised by the researcher and a Portland State University Speech Pathologist/ Clinical Supervisor. In order to devise these rules for evaluating vocal effort for this study's population, the researcher and a Portland State University Speech Pathologist listened to the training tapes and separately rated the vowel samples for vocal effort. Individual judgements were made based upon " 1 " representing normal phonation and " 9 " representing most severe vocal effort. Ratings were compared and found to be in relatively close agreement, within two scaled values for 87 percent of the judgements. Discussion ensued and the guidelines in Appendix $\mathrm{H}$ reflect a composite of the features that were attended to in order to arrive at a scaled value for vocal effort. During the training/rating sessions, the judges were seated approximately nine feet from and facing the loudspeaker. Part I (training for vowels) continued for $2 \frac{1}{2}$ hours. Practice and discussion ensued for the first forty-five minutes and then the judges rated groups of fifteen vowel samples. Five of the fifteen samples were repetitions. Satisfactory inter-and intra-judge reliability was achieved for the second group of fifteen vowel samples. Judgements between pairs of judges varied no more than \pm 1 scaled value for 90 
percent of the samples. Intra-judge reliability was \pm 1 scaled value or better for all of the five repetitions. This degree of inter- and intra-judge reliability was considered a satisfactory indication that the judges were sufficiently trained and were in relative agreement as to what voice quality features were most important to attend to in determining severity of vocal effort.

Part II (individual judgement of experimental vowel samples) proceeded for sixty minutes, inclusive of a 10-minute break. During this time, the judges rated sixty-six vowel samples using the 9-point scale. The sixty-six vowel samples represented two vowels each per twenty-eight subjects $(/ a /$ and $/ u /)$, plus ten randomly chosen repetitions.

Part III of the training and rating session consisted of learning how to apply the 9-point scale to samples of speech and individually rating the experiment's speech samples. The training tape for speech consisted of a total of nine samples obtained from four hearingimpaired children and two normal hearing children. These children did not participate in the actual study. Additionally, in order that extreme values of the severity scale be represented on the training tape, speech samples from three hearing-impaired subjects who participated in the study were included. The eleven recorded speech samples used for the training tape were prepared by assigning the order of presentation at random, equalizing the loudness levels, and playing the recordings backwards. The steps used to prepare these training tapes were identical to the procedures used in preparing this study's data. 
Forty minutes were spent during Part III listening to the speech training tape and discussing use of the rating scale. During this training period, inter-judge agreement was approximately 80 percent \pm 1 scaled value when comparing pairs of judges. The final vocal rating task, consisting of individual judgements for the thirty-three experimental speech samples, lasted forty minutes. This included a 5-minute break. The thirty-three speech samples represented one set of twenty single-word responses per subject, plus five repetitions chosen at random.

The degrees of intra-judge reliability for the experimental vowel and speech samples were examined by comparing individual judge's ratings on repeated stimuli. For the vowel samples, out of ten repetitions presented to the judges, 63 percent were absolute replications, 27 percent varied one scaled value, and 10 percent deviated two on the 9-point scale. For the speech samples, out of five repetitions presented to the judges, 53 percent were exact replications, 27 percent varied one scale value, and 20 percent varied two on the 9-point scale.

Inter-judge reliability was assessed by computing Pearson $r$ product moment correlations. Tables I, II, and III present the correlation coefficients indicating the degrees of association between ratings by pairs of judges for the vowels $/ a /$ and $/ u /$ and for the speech samples. Pearson $r$ product moment coefficients revealed positive correlations between the ratings of pairs of judges that were significant at the .005 level. With the exception of one comparison (Judges C and B for the vowel $/ \mathrm{u} /$ ), all values fall into the correla- 
TABLE I

INTER-JUDGE RELIABILITY FOR /a/ RATINGS

\begin{tabular}{ccc}
\hline & J udge $_{\text {Judge }}$ & \\
A & $.82 t$ & \\
B & $.75 t$ & $.80 t$ \\
\hline \multicolumn{4}{c}{$t p<.005$}
\end{tabular}

TABLE II

INTER-JUDGE RELIABILITY FOR /u/ RATINGS

\begin{tabular}{|c|c|}
\hline & $J$ u d $g$ e \\
\hline Judge & A $\quad$ B \\
\hline
\end{tabular}

A

B . .76t

c .86t $\quad .69 t$

$f p<.005$ 
TABLE III

INTER-JUDGE RELIABILITY FOR SPEECH RATINGS

$\overline{\text { Judge }} \quad A^{J \text { u d } g \text { e }}$

$\mathbf{A}$

$\begin{array}{lrr}\text { B } & .79 t \\ \text { c } & .78 t \quad .82 t\end{array}$

tion range described by Guilford (1956) as being indicative of high strengths of correlation.

In order to assess the consistency of inter-judge reliability across the three stimuli judged per subject $(/ a /, / u /$, and speech sample), canonical correlation coefficients were calculated. The analyses were performed utilizing the canonical correlation, "Cancorr," subprogram of the Statistical Package for the Social Sciences (Nie, Hu11, Jenkins, Steinbreaner, and Bent, 1975) on a Honeywell 66-20 computing system. The eigenvalues, coefficients, Chi-square values, degrees of freedom, and significance are presented in Table IV.

The canonical coefficients indicated how well the weighted combination of three stimuli's ratings, judged by one listener, predicted the weighted combination of three stimuli's ratings as judged by another listener. When this study's three judges were examined in pairs, canonical correlation coefficients of $+.94,+.89$, and +.91 were obtained. All of these correlations were significant at the .001 
TABLE IV

CANONICAL CORRELATIONS FOR RATINGS OF PAIRS OF JUDGES

\begin{tabular}{cccccc}
\hline $\begin{array}{c}\text { Pairs of } \\
\text { Judges }\end{array}$ & $\begin{array}{c}\text { Eigen- } \\
\text { values }\end{array}$ & $\begin{array}{c}\text { Canonical } \\
\text { Coefficient }\end{array}$ & $\begin{array}{c}\text { Chi-square } \\
\text { Value }\end{array}$ & d.f. & $\begin{array}{c}\text { Signif- } \\
\text { cance }\end{array}$ \\
\hline A/B & .88 & .94 & 55.19 & 9 & .000 \\
B/C & .79 & .89 & 50.16 & 9 & .000 \\
C/A & .83 & .91 & 62.17 & 9 & .000 \\
\hline
\end{tabular}

level of significance as indicated by the Chi-square values. The eigenvalues indicated the amount of shared variance in one canonical variate (weighted score) relative to another canonical variate (another judge's weighted score). For example, 88 percent of the variance in Judge $A$ 's total judgements could be explained by the variance in Judge B's total judgements. These results indicate a strong pattern of association across three judged items and three judges.

Due to the high degree of inter-judge agreement, a single perceptual rating for each vowel and speech sample was derived by averaging the three judges' individual ratings.

\section{Statistical Analys is of Data}

Research Questions. The first question of this study was, "What is the nature of the association, if any, between the measures of spectral noise and perceived degrees of vocal effort for samples of hearing-impaired and normal hearing children?" This was assessed by computing the following four Pearson $r$ product moment correlations: 


$\begin{array}{ccc}\text { Perceived } & \text { Perceived } & \text { Perceived } \\ \text { Harshness } & \text { Harshness } & \text { Harshness } \\ \text { /a/ } & / \mathrm{u} / & \text { Speech }\end{array}$

Spectral Noise Leve1 /a/

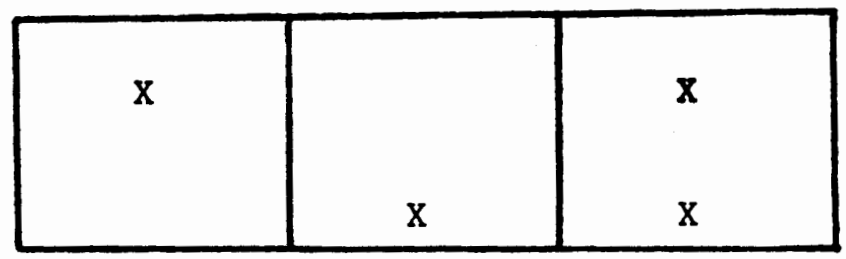

Spectral Noise Level $/ \mathrm{u} /$

for the following four groups of children ( $N$ 's):

$\mathrm{N}=28$ Hearing-impaired and normal hearing children $\mathrm{n}=10$ Normal hearing children

$\mathrm{n}=8$ Total Communication hearing-impaired children $\mathrm{n}=10$ Oral/Aural hearing-impaired children

Thus, a total of sixteen Pearson $r$ product moment correlations were computed in order to answer question one.

The second question was, "Is a heterogeneous sample of hearingimpaired children different in spectral noise levels from normal hearing children?" To answer this question, two t-tests for independent means were computed. One t-test compared the eighteen hearingimpaired children vs. the normal children in terms of spectral noise levels for $/ a /$. The second t-test compared these two groups of children in terms of spectral noise levels of $/ \mathrm{u} /$.

In order to answer the third question, "Is a heterogeneous sample of hearing-impaired children different in perceived vocal effort from normal hearing children?" three t-tests for independent means were computed. One t-test compared the eighteen hearingimpaired children to the ten hearing children in terms of the perceived harshness for $/ a /$. Another t-test compared these two populations for perceived degree of harshness for $/ u /$ and a third $t$-test for perceived vocal effort for speech. 
Two t-tests for independent means were computed to assess the fourth question: "Are hearing-impaired students attending a Total Communication educational program different in spectral noise levels from Oral/Aural hearing-impaired students?" One t-test compared the eight Total Communication children to the ten Oral/Aural children in terms of the spectrographic measure of noise for $/ a /$ and the second t-test compared these two groups in terms of the spectrographic measure of noise for $/ \mathrm{u} /$.

The final question of this study was, "Are hearing-impaired students attending a Total Communication educational program different in perceived vocal effort from Oral/Aural hearing-impaired students?" In order to assess this question, three t-tests for independent means were computed which compared the two groups of hearing-impaired children. One $t$-test compared the Total Communication and Oral/Aural students in terms of perceived degree of harshness for $/ a /$, a second $t$-test for perceived harshness for $/ u /$, a third $t$-test for perceived harshness during speech. 
CHAPTER III

RESULTS AND DISCUSSION

RESULTS

The purpose of this study was to investigate the perceptual and acoustical correlates of vocal effort in normal hearing and severely to profoundly hearing-impaired children. Recorded vowel and speech samples were obtained from ten normal children, ten hearing-impaired children attending Oral/Aural educational programs, and eight hearingimpaired children attending Total Communication educational programs. These recordings were played to a panel of three judges who rated the vowel and speech samples for vocal effort, using a 9-point equalappearing-interval scale. In addition to these perceptual judgements, acoustical analyses of the noise components within the vowel spectra were performed. The level of inharmonic energy in each vowel sample was indexed as the mean spectral noise level. The study sought to answer five questions. The research questions and the results of the study follow.

The first question posed was:

What is the nature of the association, if any, between the measures of spectral noise and perceived degrees of vocal effort for samples of hearing-impaired and normal hearing children?

To study the relationships between the vowel mean spectral noise levels and the mean judgements of vocal effort for the vowels, scat- 
tergrams for the vowels / $\mathrm{a} /$ and $/ \mathrm{u} /$ were plotted (see Figures 3 and 4). Both of the diagrams suggested positive relationships exist between the physical (spectral noise) and perceptual (vocal effort) measurements for each of the two experimental vowels. The relationships did not appear perfect, but, in general, the more severe ratings of vocal effort were associated with higher spectral noise level means.

To further investigate the degree of association between mean spectral noise levels and rated vocal effort for each vowel, Pearson r product moment correlations were calculated. Table $\mathrm{V}$ presents the correlation coefficients indicating the degrees of association between the physical and perceptual measurements obtained from the twentyeight subjects participating in this study. Additionally, Table V presents the correlation coefficients between these two measurements

TABLE V

CORRELATION COEFFICIENTS FOR VOWEL RATINGS AND VOWEL SPECTRAL NOISE LEVELS

\begin{tabular}{|c|c|c|c|c|}
\hline Vowe 1 & $\mathrm{~N}=28$ & $\begin{array}{l}n=10 \\
\text { Norma l Hrg. }\end{array}$ & $\begin{array}{c}n=10 \\
\text { Oral/Aura1 }\end{array}$ & $\begin{array}{c}n=8 \\
\text { Total Com. }\end{array}$ \\
\hline$|a|$ & $.69 *$ & $.71 *$ & $.56 *$ & $.84 *$ \\
\hline$/ \mathrm{u} /$ & $.47 *$ & .44 & .09 & $.51 * *$ \\
\hline
\end{tabular}




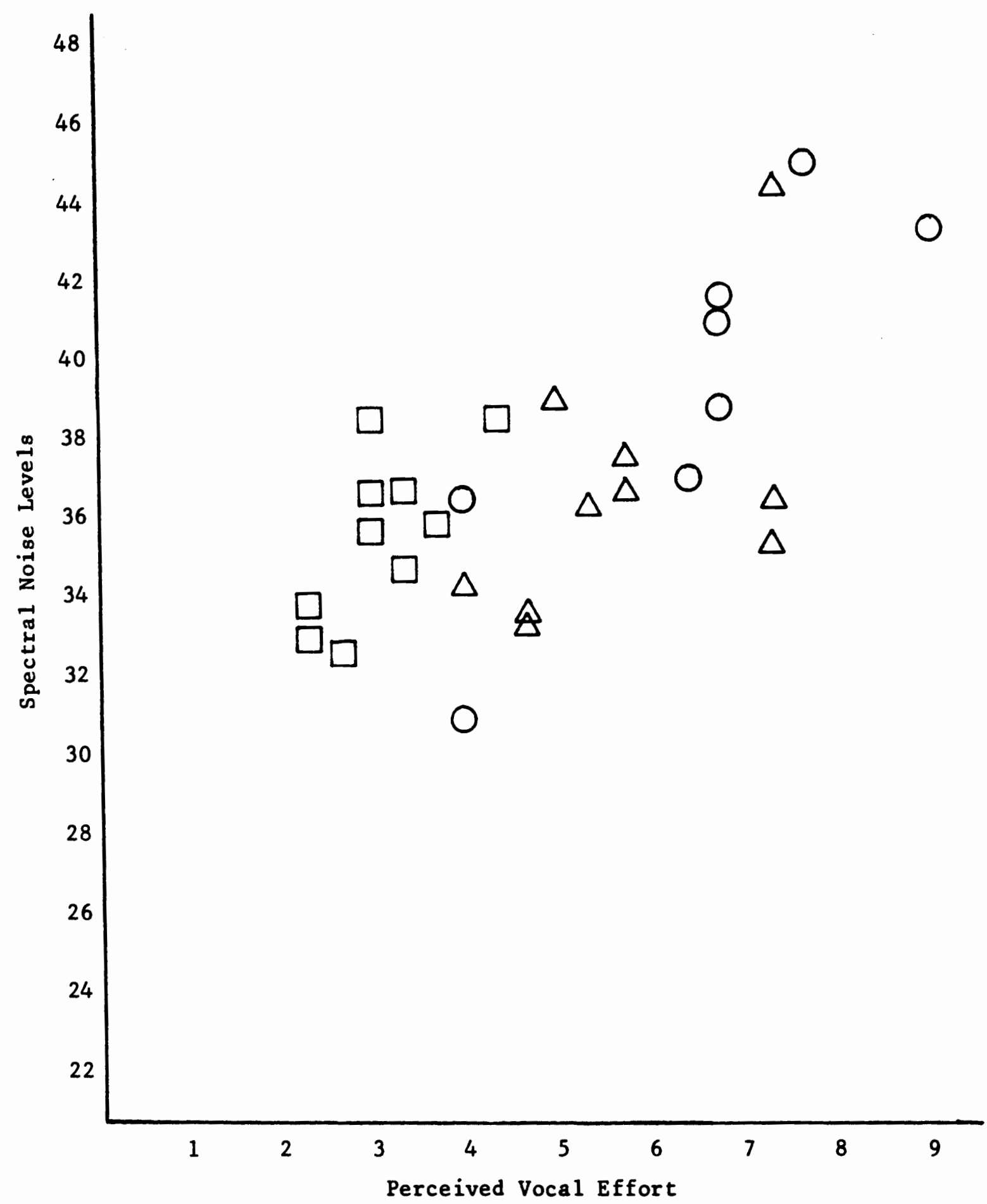

Figure 3. Mean spectral noise levels and mean vocal effort ratings for the vowel $/ a /$ produced by 10 normal hearing children $(\square)$, 10 Oral/Aural hearing-impaired children $(\Delta)$, and 8 Total Communication hearing-impaired children $(O)$. 


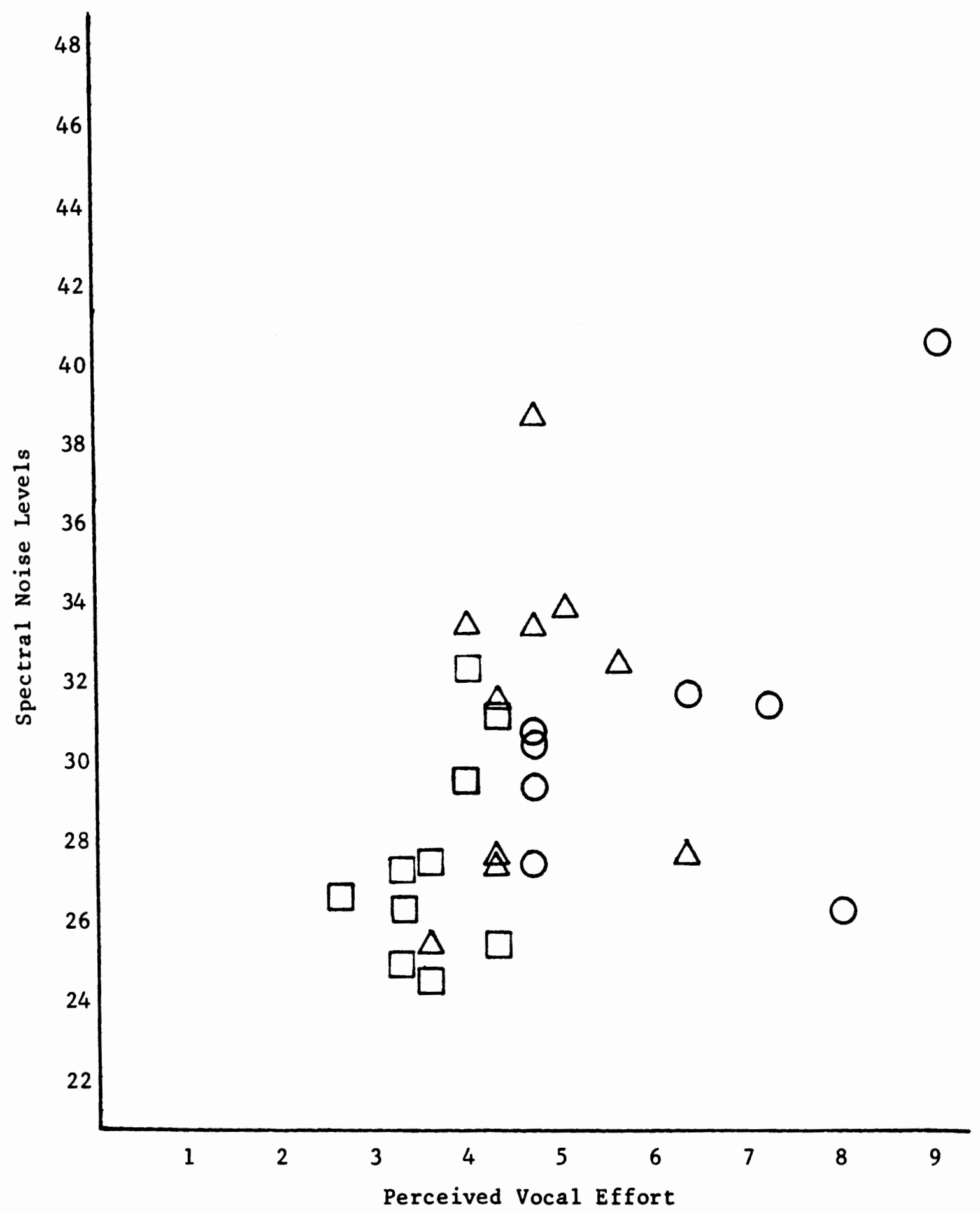

Figure 4. Mean spectral noise levels and mean vocal effort ratings for the vowel / $/$ produced by 10 normal children $(\square), 10$ Oral/Aural hearing-impaired children $(\Delta)$, and 8 Total Communication hearing-impaired children $(O)$. 
(the spectral noise levels and the mean vocal effort ratings) for each of three subsets of this study's population. The three subsets were: the group of ten normal hearing children, the ten hearing-impaired subjects attending Oral/Aural programs, and the eight hearing-impaired subjects attending Total Communication programs.

A significant and positive correlation would imply the physical measurement of vowel spectral noise is related to these children's perceived vocal effort for vowels. Computation of Pearson $r$ product moment coefficients revealed significant and positive correlations between the physical and perceptual measurements of both vowels for the group of twenty-eight normal hearing and hearing-impaired subjects. The correlation coefficient for the vowel /a/ (+.69) was larger than that computed for the vowel $/ u /(+.47)$. Both of these values fall into the correlation range described by Guilford (1956) as indicating moderate strengths of relationships. Guilford states that the coefficients .40 and .70 are roughly the low and high values describing moderate relationships, respectively.

Additionally, significant moderate or high correlations are indicated for each population subset in terms of the physical and perceptual measurements of the vowel $/ a /$. For the vowel /u/, however, significant correlations were not found for two out of the three population subsets, the Oral/Aural hearing-impaired children and the normal hearing children. Based on these findings it appears there is, in general, a substantial and significant relationship between mean spectral noise levels and mean perceived vocal effort ratings for the vowe $1 / a /$. The relationship is not as predictable for the vowe $1 / u /$, 
however, except with the Total Communication subjects.

Pearson $r$ product moment coefficients also were calculated to investigate the degrees of association between the mean spectral noise levels for each vowel and the rated vocal effort for speech. Table VI presents the correlation coefficients indicating the degree of association between average speech ratings and the mean spectral noise levels for the vowels $/ a /$ and $/ u /$.

\section{TABLE VI}

CORRELATION COEFFICIENTS FOR SPEECH RATINGS AND

VOWEL SPECTRAL NOISE LEVELS

\begin{tabular}{|c|c|c|c|c|}
\hline Vowe 1 & $N=28$ & $\begin{array}{c}n=10 \\
\text { Normal Hrg. }\end{array}$ & $\begin{array}{c}n=10 \\
\text { Oral/Aural }\end{array}$ & $\begin{array}{c}n=8 \\
\text { Total Com. }\end{array}$ \\
\hline$|a|$ & $.55 *$ & $.45 * *$ & .30 & $.57 * *$ \\
\hline$/ u /$ & $.41 *$ & .17 & -.14 & $.64 *$ \\
\hline
\end{tabular}

A significant and positive correlation would imply children's perceived vocal effort for speech is related to the physical measurement of vowel spectral noise. Computation of the Pearson $r$ product moment coefficients revealed significant and positive correlations between the twenty-eight subjects' physical measurements of vowel spectral noise and perceptual ratings for speech. The correlation coefficient comparing speech ratings to spectral noise for $/ a /(+.55)$ was once again larger than the coefficient comparing speech to the vowel $/ \mathrm{u} /(+.41)$. Both coefficients, however, fall into the range 
which implies a moderate correlation. Closer inspection of the relationships for specific population subsets reveals that the correlation coefficients are greatest for the Total Communication subjects. In fact, significant correlation coefficients were not found for the Oral/Aural population subset when comparing speech ratings to spectral noise for either vowel or for the normal hearing population when comparing speech ratings to / $/$ / spectral noise levels.

Based on these findings, it appears that there is, in general, a substantial relationship between mean vowel spectral noise levels for la/ when compared to mean perceptual vocal effort ratings for speech. Levels of spectral noise for the vowel /u/ were significantly related to perceived vocal effort for only the Total Comnunication students in this study.

To sum up, for the most part there is a significant and moderate correlation between the spectral noise levels for the vowel /a/ compared to the perceived degree of vocal effort for the production of both $/ a /$ and speech. In contrast, spectral noise levels for the vowel $/ u /$ are not significant predictors of perceived vocal effort except in the Total Communication population. Additionally, there appears to be a trend for vowel spectral noise levels to be poorer predictors of Oral/Aural hearing-impaired children's perceived vocal effort than for Total Communication or normal hearing children.

All of the above physical measurements of spectral noise levels were computed, utilizing a Hewlett Packard wave analyzer (HP 3582A). For comparison purposes, several spectra also were produced, using a General Radio wave analyzer (Type 1910-A). Different spectra were 
produced from the same vowel, using these two pieces of equipment. Upon visual inspection, the relative positions of adjacent maxima and minima points appeared approximately the same on the General Radio spectra as compared to the Hewlett Packard spectra. Spectra from the General Radio wave analyzer did appear to include more minute variations in the frequencies' energy levels, as would be expected from an instrument which produces extremely narrow-band spectra (3-Hertz bandwidth). In general, though, the relationships of the harmonics and inharmonics appeared relatively the same. Spectral noise levels were calculated from the General Radio spectra and compared with the corresponding vowel spectral noise levels derived from the Hewlett Packard instrumentation. For the three vowels compared, mean spectral noise levels did not vary more than $2 \mathrm{~dB}$.

The second experimental question was:

Is a heterogeneous sample of hearing-impaired children different in spectral noise levels from normal hearing children?

Two-tailed t-tests for independent means were used to determine the differences between the auditorily handicapped children's mean spectral noise levels for the vowels /a/ and /u/ and those spectral noise levels for the normal hearing children. The means, standard deviations, and t-test results are presented in Table VII. Additionally, the means and standard deviations for the spectral noise level measurements of both groups of subjects are graphically displayed in Figure 5. A statistically significant difference was found at the .05 level of confidence between the spectral noise levels of these two populations for the vowe $1 / u /$ only. In this study, normal hearing and 


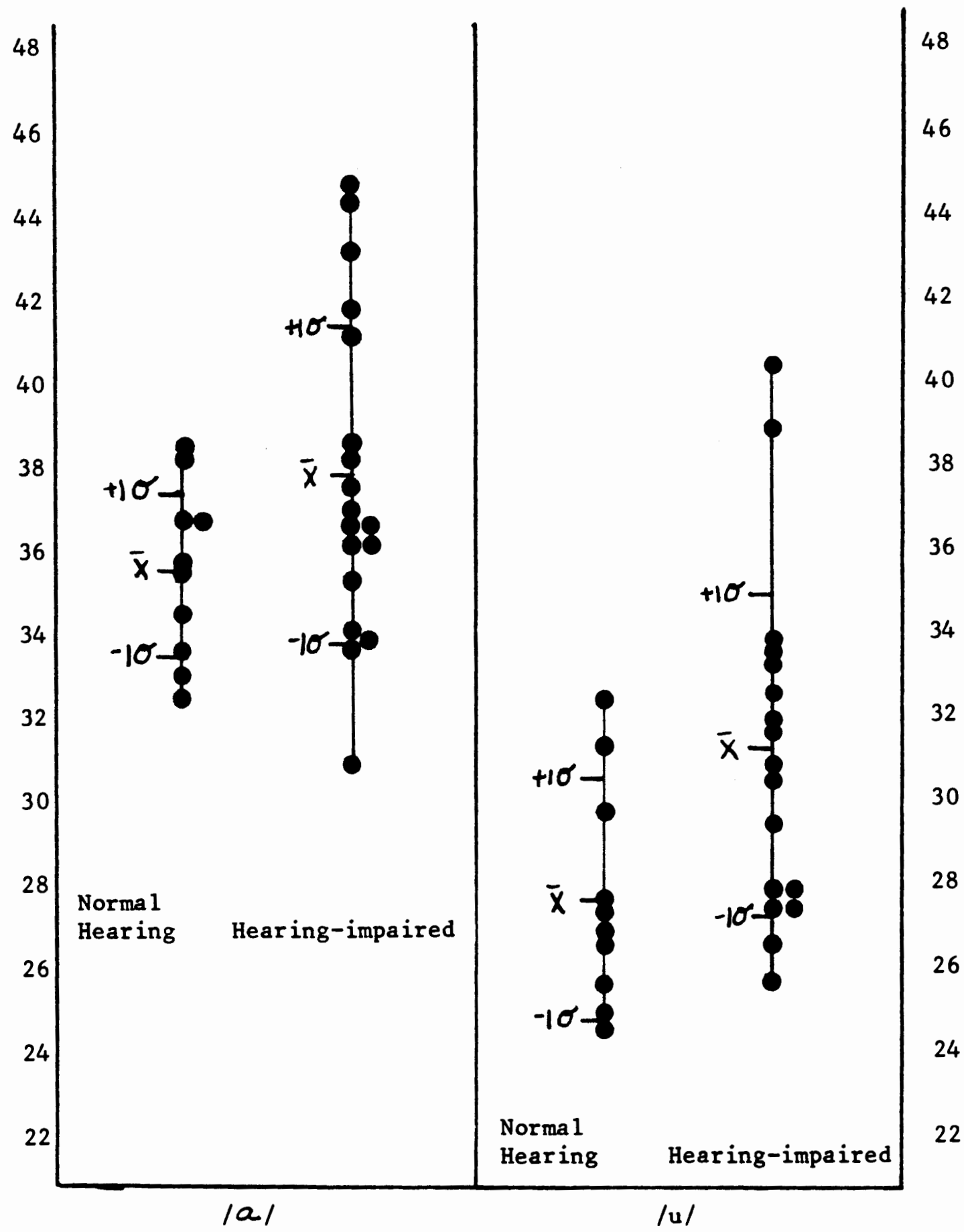

Figure 5. Spectral noise level means and standard deviations for the vowels $/ a /$ and / $/ \mathrm{a}$ produced by 10 normal hearing and 18 hearing-impaired children. 
TABLE VII

COMPARISON OF SPECTRAL NOISE LEVELS FOR NORMAL HEARING AND HEARING-IMPAIRED CHILDREN

\begin{tabular}{|c|c|c|c|}
\hline Vowe 1 & $\begin{array}{r}\text { Spectral } \\
n=10 \\
\text { Normal Hearing }\end{array}$ & $\begin{array}{l}\text { ise Levels } \\
\qquad \mathrm{n}=18 \\
\text { Hearing-Impaired }\end{array}$ & $t$ \\
\hline$|a|$ & $\begin{array}{l}\mathbf{x}=35.57 \\
S D=2.06\end{array}$ & $\begin{array}{l}x=37.73 \\
S D=3.93\end{array}$ & 1.60 \\
\hline$/ \mathrm{u} /$ & $\begin{array}{l}x=27.53 \\
S D=2.64\end{array}$ & $\begin{array}{l}\mathbf{x}=31.11 \\
S D=3.97\end{array}$ & $2.54 * *$ \\
\hline
\end{tabular}

hearing-impaired children were not significantly differentiated by mean spectral noise levels of the vowel /a/. Normal hearing and severely to profoundly hearing-impaired children were found significantly different in terms of the physical measurement for vocal effort for the vowel /u/. Specifically, hearing-impaired children demonstrated statistically significant higher spectral noise levels for the vowe $1 / \mathrm{u} /$.

The third experimental question was:

Is a heterogeneous sample of hearing-impaired children different in perceived vocal effort from normal hearing children?

Two-tailed t-tests for independent means were used to determine the differences between the auditorily handicapped children's perceived degree of vocal effort for the vowels $/ a /$ and $/ u /$ and for speech as compared to those perceptual ratings for the normal hearing children. The means, standard deviations, and t-test results are 
presented in Table VIII. Additionally, the means and standard deviations for the perceptual ratings of both groups of subjects are graphically displayed in Figure 6. Statistically significant differences were found at the .01 level of confidence between the perceived vocal effort ratings of these two populations for all three stimuli judged. In this study, the normal hearing and severely to profoundly hearing-impaired children were significantly different in terms of perceived vocal effort. Specifically, the normal hearing children received significantly lower ratings for vocal effort during the production of speech and vowels than the severely to profoundly hearingimpaired children.

\section{TABLE VIII}

COMPARISON OF PERCEPTUAL RATINGS FOR NORMAL HEARING AND HEARING-IMPAIRED CHILDREN

\begin{tabular}{|c|c|c|c|c|c|}
\hline \multicolumn{6}{|c|}{ Ratings } \\
\hline & Norma & $\begin{array}{l}n=10 \\
1 \text { Hearing }\end{array}$ & Hear in & $\begin{array}{l}n=18 \\
g \text {-Impaired }\end{array}$ & $t$ \\
\hline$|a|$ & $\begin{array}{l}\mathbf{x} \\
\text { SD }\end{array}$ & $\begin{array}{l}=3.13 \\
=.61\end{array}$ & $\begin{array}{l}\mathbf{x} \\
\mathrm{SD}\end{array}$ & $\begin{array}{l}=6.00 \\
=1.45\end{array}$ & $5.92 *$ \\
\hline$/ \mathrm{u} /$ & $\begin{array}{l}\mathbf{x} \\
\mathrm{SD}\end{array}$ & $\begin{array}{l}=3.66 \\
=\quad .52\end{array}$ & $\begin{array}{l}\mathbf{x} \\
\mathrm{SD}\end{array}$ & $\begin{array}{l}=5.35 \\
=1.47\end{array}$ & $3.47 *$ \\
\hline Speech & $\begin{array}{l}x \\
S D\end{array}$ & $\begin{array}{l}=3.80 \\
=.98\end{array}$ & $\begin{array}{l}x \\
S D\end{array}$ & $\begin{array}{l}=6.31 \\
=1.26\end{array}$ & $5.42 *$ \\
\hline
\end{tabular}

${ }^{*} \mathrm{p}<.01$ 


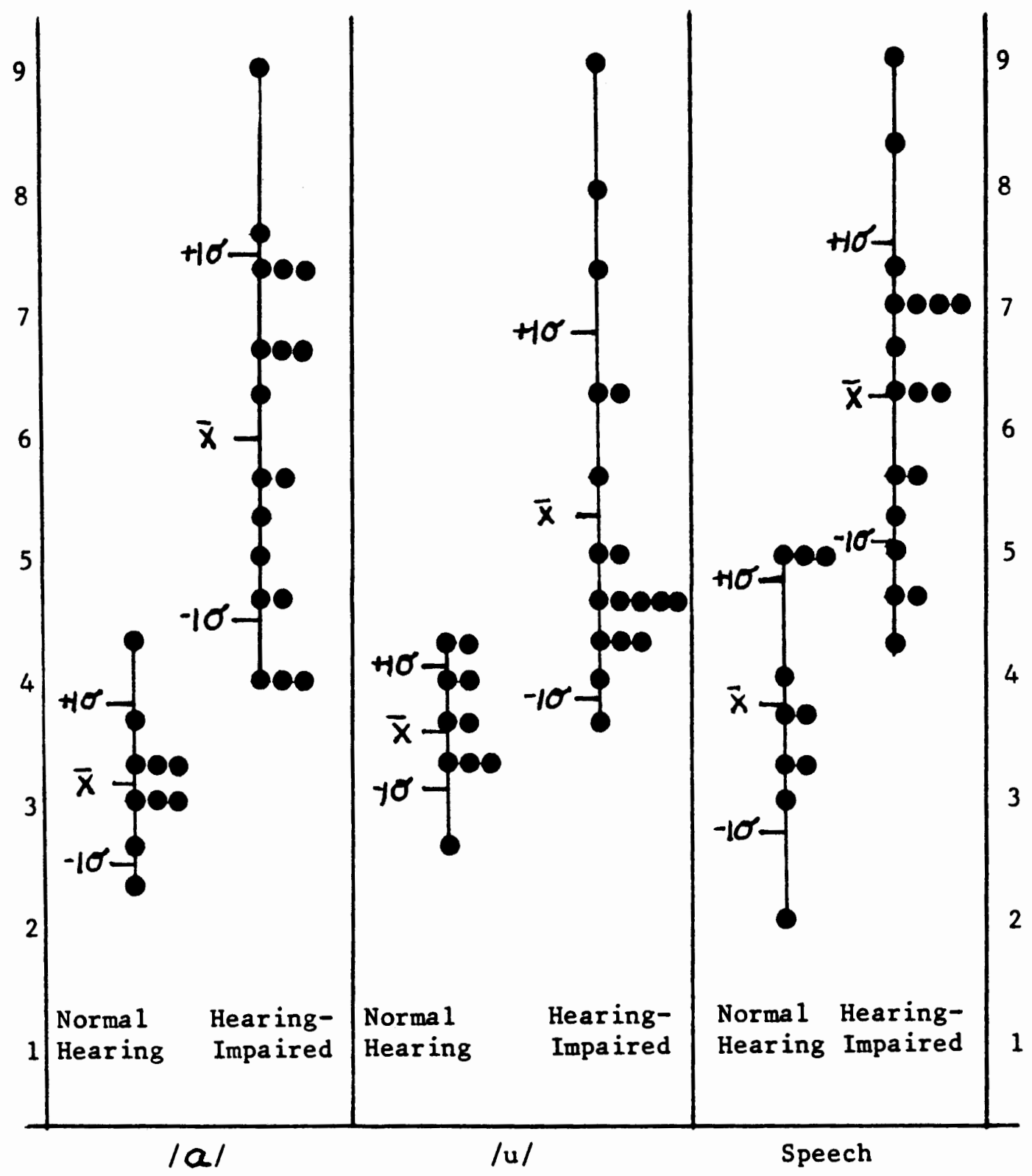

Figure 6. Means and standard deviations for perceived vocal effort ratings for the vowe $18 / a /$ and $/ u /$ and speech produced by 10 normal hearing and 18 hearing-impaired children. 
The fourth experimental question was:

Are hearing-impaired students attending a Total

Communication educational program different in spectral

noise levels from Oral/Aural hearing-impaired students?

Two-tailed t-tests for independent means were used to determine the differences between the Total Communication children's spectral noise levels for the vowels $/ a /$ and $/ u /$ and those spectral noise measures for the Oral/Aural students. The means, standard deviations, and t-test results are presented in Table IX. Additionally, the means and standard deviations for the spectral noise level measurements of both groups of hearing-impaired children are graphically displayed in Figure 7. No statistically significant difference was found at the

TABLE IX

COMPARISON OF SPECTRAL NOISE LEVELS FOR ORAL/AURAL AND TOTAL COMMUNICATION STUDENTS

\begin{tabular}{|c|c|c|c|c|}
\hline & \multicolumn{3}{|c|}{ Ratings } & \multirow[b]{2}{*}{$t$} \\
\hline & $\begin{array}{c}n=10 \\
\text { Oral/Aural }\end{array}$ & Total & $\begin{array}{l}n=8 \\
\text { Communication }\end{array}$ & \\
\hline$|a|$ & $\begin{array}{l}x=36.53 \\
S D=3.15\end{array}$ & & $\begin{aligned} & =39.23 \\
D & =4.48\end{aligned}$ & 1.50 \\
\hline$/ \mathrm{u} /$ & $\begin{array}{l}x=31.18 \\
S D=4.02\end{array}$ & $\begin{array}{l}\mathbf{x} \\
S D\end{array}$ & $\begin{aligned} & =31.02 \\
D & =4.17\end{aligned}$ & 0.08 \\
\hline
\end{tabular}

.05 level of confidence between the spectral noise levels of these two groups of hearing-impaired children. In this study, hearing-impaired children attending Total Communication programs were not significantly different in spectral noise levels from hearing-impaired children attending Oral/Aural programs. 


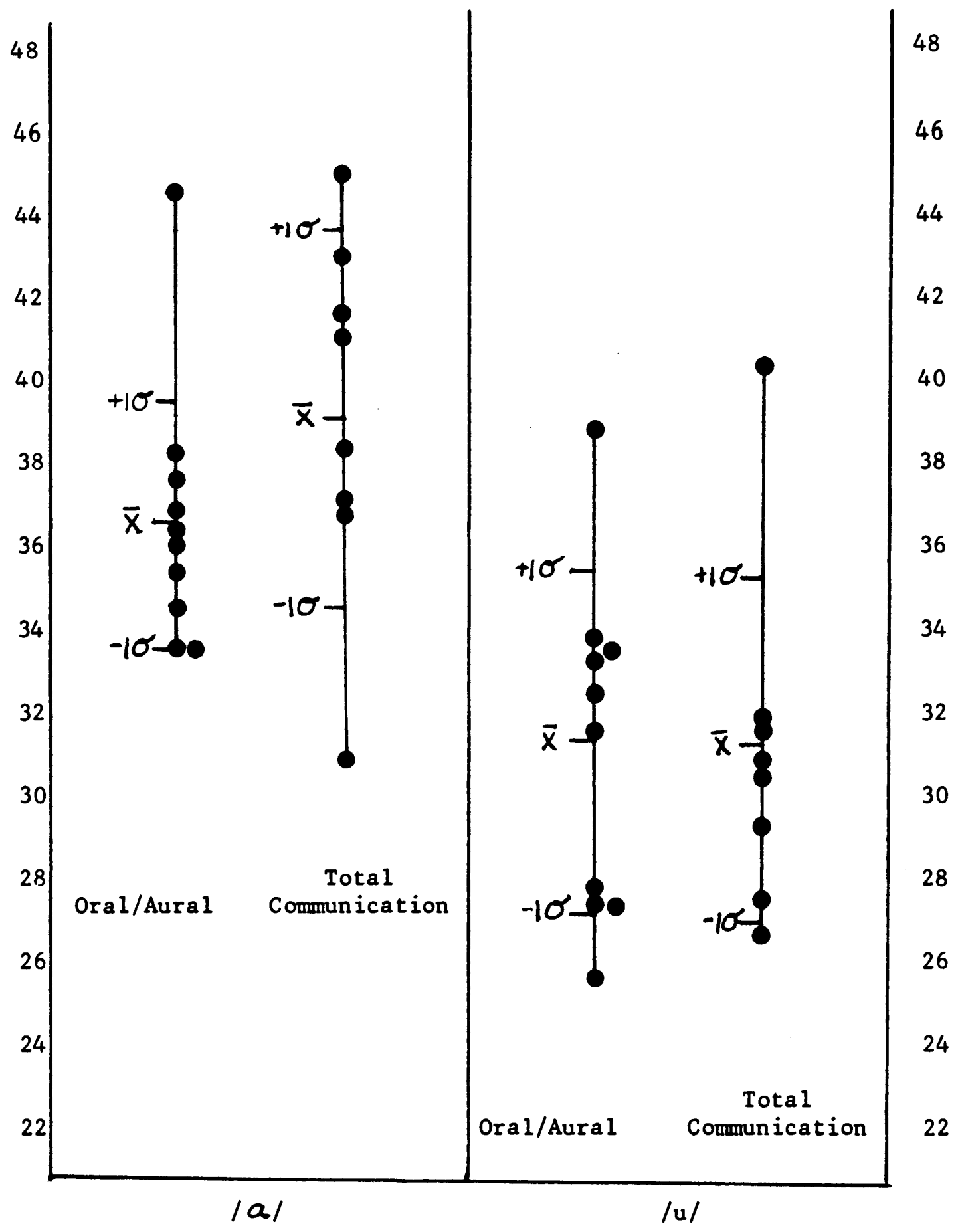

Figure 7. Spectral noise level means and standard deviations for the vowels $/ a /$ and /u/ produced by 10 Oral/Aural and 8 Total Communication hearing-impaired children. 
The fifth experimental question was:

Are hearing-impaired students attending a Total Communication educational program different in perceived vocal effort from Oral/Aural hearingimpaired students?

Two-tailed t-tests for independent means were used to determine the differences between the Total Communication children's perceived degree of vocal effort for the vowels $/ a /$ and $/ u /$ and for speech compared to those perceptual ratings for the Oral/Aural children. The means, standard deviations, and t-test results are presented in Table $X$. Additionally, the means and standard deviations for the perceptual ratings of both groups of subjects are graphically displayed in Figure 8. Statistically significant differences were found between

TABLE X

COMPARISON OF PERCEPTUAL RATINGS FOR ORAL/AURAL AND TOTAL COMMUNICATION STUDENTS

\begin{tabular}{|c|c|c|c|c|c|c|}
\hline & \multicolumn{5}{|c|}{ Ratings } & \multirow[b]{2}{*}{$\mathbf{t}$} \\
\hline & Ora & $\begin{array}{l}n=10 \\
1 / \text { Aura } 1\end{array}$ & Total & & $\begin{array}{l}n=8 \\
\text { mmunication }\end{array}$ & \\
\hline$|a|$ & $\begin{array}{l}x \\
S D\end{array}$ & $\begin{array}{l}=5.70 \\
=1.22\end{array}$ & & $\begin{array}{l}\mathrm{x}= \\
\mathrm{SD}=\end{array}$ & $\begin{array}{l}=6.37 \\
=1.69\end{array}$ & .98 \\
\hline$/ \mathrm{u} /$ & $\begin{array}{l}x \\
S D\end{array}$ & $\begin{array}{l}=4.70 \\
=\quad .79\end{array}$ & & $\begin{array}{l}\mathbf{x}= \\
\mathrm{SD}=\end{array}$ & $\begin{array}{l}=6.16 \\
=1.76\end{array}$ & $2.36 * *$ \\
\hline Speech & $\begin{array}{l}x \\
S D\end{array}$ & $\begin{array}{l}=5.60 \\
=1.01\end{array}$ & & $\begin{array}{l}\mathbf{x}= \\
\mathrm{SD}=\end{array}$ & $\begin{array}{l}=7.20 \\
=\quad .95\end{array}$ & $3.42 *$ \\
\hline
\end{tabular}

$$
\begin{aligned}
* p & <.01 \\
\star \star p & <.05
\end{aligned}
$$




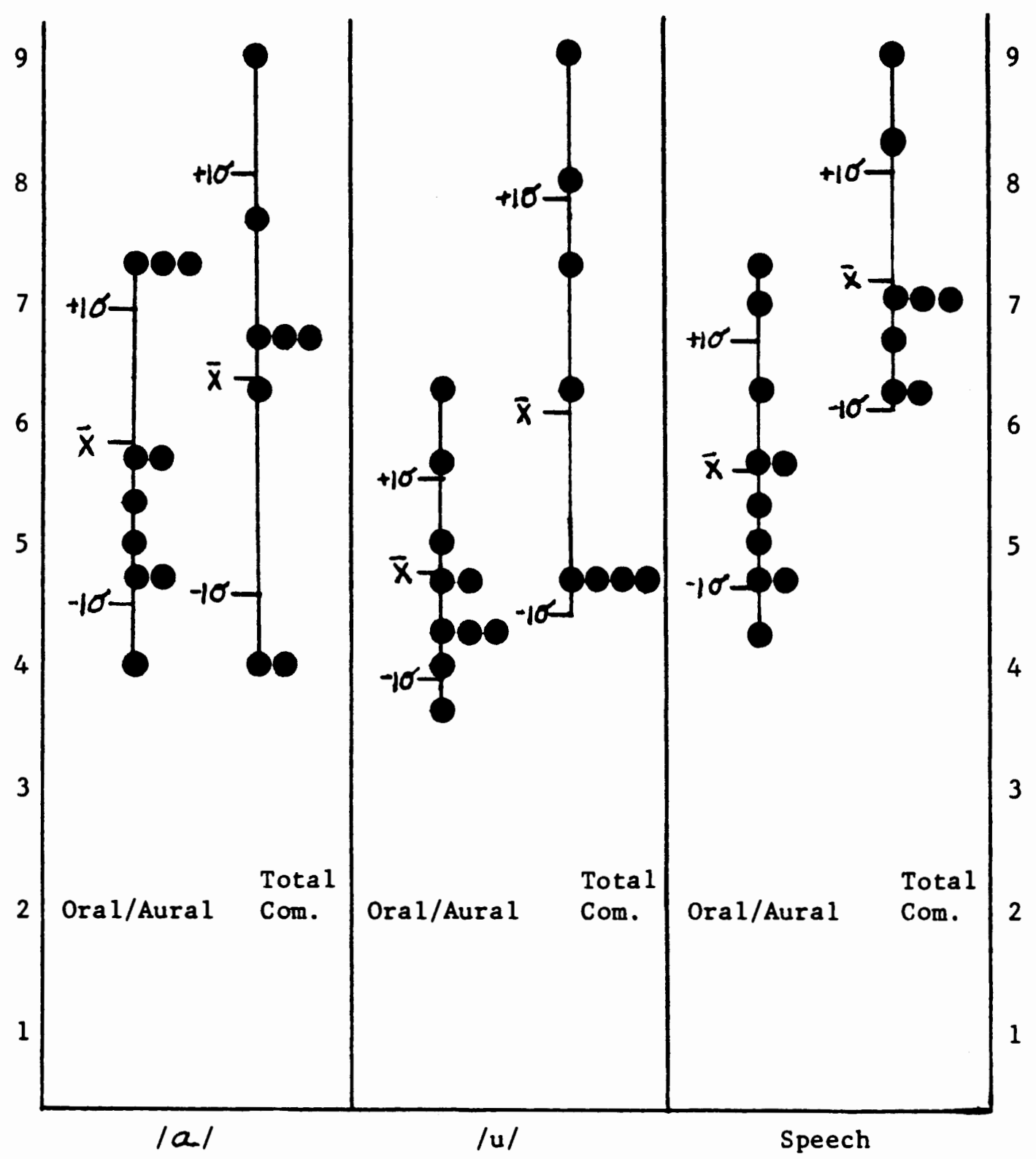

Figure 8. Means and standard deviations for perceived vocal effort ratings for the vowels $/ a /$ and $/ u /$ and speech produced by 10 Oral/Aural and 8 Total Communication hearing-impaired children. 
the perceived vocal effort ratings obtained for speech and the vowel /u/ for these two groups of hearing-impaired children. Statistical significance was found at the .01 and .05 level of confidence for speech and the vowel /u/, respectively. No statistically significant difference was found when the Total Communication children's perceived vocal effort for $/ a /$ was compared to that of the Oral/Aural group. Based on these findings, the Total Communication hearing-impaired children were perceived as demonstrating significantly greater vocal effort than the Oral/Aural children for the production of speech and the vowe $1 / \mathrm{u} /$.

\section{DISCUSSION}

This study sought to investigate the perceptual and acoustical features of vocal effort for normal hearing and hearing-impaired children. The degree of perceived vocal effort for vowels and speech was evaluated, using a 9-point equal-appearing-interval scale. In order to obtain a physical measurement for vocal effort, the amount of inharmonic (noise) components in the vowel spectra was indexed as the spectral noise level.

This study appears to be unique in attempting to obtain physical and perceptual data for vocal effort on normal hearing and hearingimpaired children. To this researcher's knowledge, no previous attempts to look at this young population in terms of vocal effort or harshness measures have been published. This study did borrow and adapt, however, certain methodologies from previous research which examined the acoustical and perceptual features of normal adults 
(Sansone and Emanual, 1970) and hearing-impaired adults (Whitehead and Lieberth, 1979). Major methodological modifications from previous studies were effected in the present study in order to accomodate the young population in question. Specifically, digital wave analysis instrumentation was used which allowed a simplified procedure for obtaining the vowel samples.

\section{Acoustical Measurement of Vocal Effort}

Although the methodology was dissimilar, the results of the first question of this study partially support the findings of Sansone and Emanual (1970) and Whitehead and Lieberth (1979) in their investigations of the acoustical correlate for perceived vocal roughness and harshness. When normal hearing adults sustained five vowels normally and with simulated roughness, Sansone and Emanual found very high correlations $(>+.90)$ between perceived roughness and vowel spectral noise levels. Similarly, Whitehead and Lieberth found that profoundly hearing-impaired adults who were perceived as demonstrating greater vocal tension/harshness for the vowels $/ a /$ and $/ u /$, exhibited vowel spectra with significantly higher spectral noise levels. In the present study involving both normal hearing and hearing-impaired children, vowel spectral noise levels also were found predictive of perceived vocal quality. In most cases, significant correlations of moderate strengths ranging from +.41 to +.69 were found between the acoustical and perceptual measures of vocal effort.

The results of this study suggest that the Hewlett Packard wave analyzer used in this research may be a very useful tool whose 
applications are worth pursuing. Specifically, use of the Hewlett Packard instrumentation allows more flexibility in collecting vowel samples used for spectral analysis. This is a particularly critical feature when examining children, since it seems more difficult to train young children to sustain uniform and predetermined vocal intensities for several seconds than adults. The constraints of the instruments used in previous studies have precluded looking at children. This and several other methodological differences existed between the present study and previous ones. More detailed discussion of contrasting procedures follows.

A major methodological difference between the present study and previous studies was the type of wave analyzer used to produce vowe 1 spectra. Specifically, Sansone and Emanual (1970) used a General Radio wave analyzer (Model 1910-A) in its 3-Hertz bandwidth mode and Whitehead and Lieberth (1979) used a General Radio wave analyzer (Model 1523-P4) in its 10-Hertz bandwidth mode. For this study, a Hewlett Packard digital wave analyzer was used which functioned in its 15-Hertz bandwidth mode. A possibility exists that the narrower bandwidth instruments are crucial for clear spectrographic presentation of noise components. It should be noted, however, that whitehead and Lieberth's reported results were almost equally and highly correlated as Sansone and Emanual's. This occurred in spite of the fact that Whitehead and Lieberth used a bandwidth mode 7 Hertz larger. Additionally, comparison of this study's vowel spectra produced on General Radio (3-Hertz bandwidth) and Hewlett Packard (15-Hertz bandwidth) wave analyzers did not appear to reveal differences which would 
significantly alter the indexed levels of spectral noise. The comparisons that were conducted involved only three vowel samples, however, and therefore the possibility that bandwidth differences could significantly alter spectral noise measurements could be looked at more closely. Nevertheless, based upon this pilot investigation, the inherently increased accuracy built into the digital Hewlett Packard wave analyzer would seem to overshadow any differences resulting from larger bandwidths.

A second major difference between the present study and previous studies was the procedure for obtaining the vowel samples. Use of the General Radio wave analyzer required that Sansone and Emanual (1970) and Whitehead and Lieberth (1979) collect vowel samples which were sustained five to seven seconds, produced at $75 \mathrm{dBSPL}$, and exhibited no more than $\pm 1 \mathrm{~dB}$ intensity variations. These rigorous conditions were not required when using the Hewlett Packard wave analyzer in the present study. Since the Hewlett Packard wave analyzer performed the digital analysis in approximately $100 \mathrm{msec}$, collection of vowel samples exhibiting one-second durations were amply long. Additionally, rather than requiring the children in this study to produce vowels at uniform intensities, this researcher elected to equalize the intensities after collection of the recorded vowels. In order to compare the level of inharmonic components from one vowel spectra to another, it is necessary to introduce the signal into the wave analyzer at a uniform intensity. The only difference between studies in this regard is that instead of demanding that the subjects compensate for this instrumental requirement, intensity equalization was 
performed mechanically. This procedure actually resulted in less variation of intensity levels being fed into the wave analyzer and, therefore, greater accuracy.

These procedural differences may be significant. Vocal harshness/tension or effort is cited in the literature as related to specific muscular and/or generalized tension (Boone, 1977). The effects of requiring an individual with little, if any, useful auditory feedback to sustain phonation at a constant and uniform intensity is conceivably a stressful situation which may provoke increased muscular tension. Even with the simplified procedures used in this study, many of the hearing-impaired children exhibited difficulty in meeting the requirements for vowel productions. The Oral/Aural hearingimpaired children required an average of four to five trials before they produced a target vowel of sufficient duration and the Total Communication children required an average of seven to eight practice trials. There is a basic assumption in this study, as in previous studies, that the recorded vowels are representative samples of each subject's typical phonations. It is interesting to speculate, however, regarding the actual validity of measurements taken from vowe 1 samples produced under artificial and perhaps stress-provoking situtions. To sum up, the demands dictated by use of the General Radio wave analyzer were more severe than those required for the present study. Use of the Hewlett Packard wave analyzer offers greater flexibility in data collection and places fewer demands upon the subject. The young age range of the present study's subjects represents another major deviation from previous studies. The normal subjects in 
Sansone and Emanual's (1970) investigation were twenty-three through thirty-three years of age; the hearing-impaired subjects in Whitehead and Lieberth's study were nineteen through twenty-four years of age. Subjects in the present investigation were seven through eleven years of age. The ramifications of this difference upon perceptual judgements are unknown. Research describing differences in the voice quality of children vs, adults is virtually non-existent. It is conceivable, however, that age may interact with perceived voice quality. For example, the listener may tolerate different amounts of inharmonic (noise) components in the child's voice vs. the adult's voice before she perceives abnormal harshness or vocal effort. In fact, this possibility was suggested by one of the judges in this study. Judge A voluntarily commented that it would be helpful to know the exact age of each subject because that information would influence vocal effort judgements.

The perception of voice quality is multidimensional, and any analysis which attempts to correlate a single physical dimension with a multifaceted perception must acknowledge those physical dimensions which are not being specifically examined. For example, fundamental frequency was not specifically assessed in this study, but visual inspection of the vowel spectra and the locations of the first harmonics reveals several interesting observations. First of all, the fundamental frequencies for all the normal hearing children and 90 percent of the Oral/Aural hearing-impaired children were no greater than 300 Hertz. It is also interesting to note that subject number 27 demonstrated the highest fundamental frequency for /u/ ( $450 \mathrm{Hertz}$ ) 
and received a perceptual rating of "8" ("piercing") for that vowel, despite a relatively low level of spectral noise (26.32) for $/ \mathrm{u} /$. This suggests that the perception of vocal effort for children is multidimensional. While the degree of spectral noise has been shown to predict the perceived severity of vocal effort to a moderate degree in this study, it would seem likely that there are other physical parameters which also may be related to perceived vocal effort. Monsen's (1979) findings would seem to support this contention. He found that young hearing-impaired children with lower fundamental frequencies were perceived as exhibiting significantly better vocal qualities. Additiona11y, Monsen reported that fundamental frequency contours, or pitch changes, were important relative to the perceived vocal quality of hearing-impaired children.

Another interesting observation is that several children in the present study demonstrated voice qualities other than abnormal vocal effort. For example, 88 percent of the hearing-impaired and 20 percent of the normal hearing children demonstrated some degree of hypernasality. Forty percent of the normal hearing children demonstrated glottal fry during at least part of the speech sample. Again, since speech is a multidimensional phenomenon, the possibility exists that concomitant vocal qualities may interfere with the listener's perception of vocal effort and/or confound the results of spectrographic analysis.

To summarize this discussion of the acoustical measurement of vocal effort, the results of this study indicate that the Hewlett Packard wave analyzer can be successfully used to produce vowel 
spectra from normal hearing and hearing-impaired children's vowel productions. Additionally, the amount of spectral noise can be measured from the spectra produced by this instrument. Vowel spectral noise levels correlated moderately, in most cases, with perceptual ratings for vocal effort of normal hearing and hearing-impaired children. Although the physical measurement examined in this study does not seem to be, by itself, a perfect predictor of the severity of vocal effort, there is at least some significant relationship between spectral noise and perceived vocal effort for children. For this reason, the use of the Hewlett Packard wave analyzer may be valuable in research and clinical assessments of the physical correlates of vocal effort in children. This instrument's advantages include greater inherent accuracy and minimal demands upon the subjects for collection of vowel samples.

\section{Perceptual Measurement of Vocal Effort}

The perceptual scale used for vocal effort in this study was an attempt to devise descriptive guidelines to facilitate vocal effort ratings. After three hours' training, the judges demonstrated relatively high degrees of inter- and intra-judge reliability. This speaks to the success of the training sessions. It is safe to assume that the perceptual guidelines helped the judges to attend to the same features which are associated with vocal effort.

It is interesting to note that the perceptual guidelines proposed by this researcher and accepted by this study's judges represent some features which other authors have used to describe deaf voices. 
Some characteristics which appear in this study's guidelines and elsewhere are "macro-changes in pitch or loudness" (Martony, 1968; Monsen, 1979), "micro-changes in pitch or loudness" or jitter and shimmer (Monsen et a1., 1979), and the descriptors "tense" and "piercing" (Calvert and Silverman, 1975; Whitehead and Lieberth, 1979).

To further facilitate perceptual judgements, this researcher used backward playing of speech samples. In an earlier study, Sherman (1954) compared ratings for backward and forward played samples of harsh-sounding adults. She found that vocal harshness differences were more obvious when played backwards and concluded that more valid measurements of vocal harshness are available from backward playing. The present study appears unique in employing this procedure for normal hearing or hearing-impaired children. The need to use this technique in the present study seemed imperative, since normal hearing and hearing-impaired children were being compared to one another. Listening to this study's speech samples played forward, marked and distracting differences in articulation and prosody were noted between the normal hearing and hearing-impaired samples. These differences were minimized during backward playing. All the children sounded unintelligible and the prosody differences were not as apparent. The advantages of using backward recording for vocal quality judgements of the hearing-impaired population deserve further examination. It would seem that this procedure was useful in this study to help the judges attend to their assigned perceptual task.

One major disadvantage of utilizing backward playback for vocal effort ratings is the unknown effect this technique has upon pitch and 
loudness cues. In backward playback, information about pitch and loudness changes is still available, but reversed in time. For example, if a speaker progressively increases her pitch level from the beginning to end of a speech sample, during backward playback the pitch level would be presented as becoming progressively lower. Whether or not this phenomenon has a deleterious effect upon the validity of vocal effort ratings is unknown and deserves further attention.

Another possible disadvantage of using backward playback for vocal effort ratings is when glottal fry occurs in some of the speech samples. In this study, four normal hearing subjects demonstrated glottal fry during at least part of their recorded speech samples. Although glottal fry is fairly easily recognized during forward playing, during backward playing, glottal fry sounds rough. In fact, one judge remarked, "That sure sounds hoarse," when listening to backward playing of a training tape characterized by glottal fry. This presents a problem when rating vocal effort, because glottal fry is not usually associated with increased tension (Perkins, 1968).

To sum up, the perceptual scale for rating vocal effort served as a useful tool in training judges to reliably attend to certain perceptual features associated with vocal effort. Additionally, backward playing of speech samples was used to assist the judges in attending to vocal effort characteristics. These assessment strategies appeared invaluable for the present research, and further evaluation and refinement of the perceptual rating guidelines and backward playback technique are recommended, particularly for applications 
involving the hearing-impaired.

Acoustical and Perceptual Differences between

Normal Hearing and Hearing-Impaired Children

Based upon the results of this study, hearing-impaired children are perceived as demonstrating significantly greater vocal effort than normal hearing children during the production of speech and vowels. This difference was most apparent for the vowel $/ a /$, where all of the hearing-impaired subjects received a vocal effort rating of "4" (some constriction) or greater, while only one normal hearing subject received a rating at or above " $4 . "$ Additionally, hearing-impaired children tended to demonstrate higher vowel spectral noise levels, although this difference was found significant only for the vowe $1 / \mathrm{u} /$.

The difference found between normal hearing and hearing-impaired children's voice quality concurs with previous findings and statements in the literature. Calvert and Silverman (1975) state that deaf voices are often harsh and Spector et al. (1979) report that there is a higher incidence of vocal harshness/tension in the deaf than in the normal hearing population. The literature cites several possible explanations for these differences. Some researchers contend the hearing-impaired speaker demonstrates inappropriate degrees of laryngeal and vocal tract tension which results from poor control of the speech apparatus (Forner and Hixon, 1977; Monsen et al., 1979). Others speculate that the hearing-impaired speaker may attempt to increase internal feedback, in the absence of sufficient audition, by increasing muscular tension or may bring generalized inappropriate tension to more difficult communicative tasks (Willemain and Lee, 
1971). During collection of this study's data, this researcher informally noted physical signs of increased muscular tension during many of the hearing-impaired speakers' phonations. This was in contrast to the relative ease at which the normal hearing children seemed to perform the task. Specifically, the tense body postures noted in the hearing-impaired children included lifted shoulders and thorax, breath-holding prior to phonation, exaggerated breathing patterns, facial grimaces, exaggerated mouth opening and closing, and the tightening of neck muscles during phonation.

The results from the present study seem to point to a higher incidence figure for vocal effort in severely to profoundly hearingimpaired children than the percentage reported previously for severely to profoundly hearing-impaired adults. Specifically, Spector et al. (1979) reported that 11 percent of students entering the National Technical Institute for the Deaf (NTID) demonstrate a moderate to severe problem of vocal tension/harshness. In this study, however, the mean rating for normal hearing children's perceived vocal effort was 3.80 , while the mean rating for hearing-impaired children was 6.31. Thirty-nine percent of the present study's hearing-impaired children received perceptual ratings for speech that were greater than or equal to the scale value "7," which describes a "metallic" and "sharp" voice. The results from this study, therefore, indicate an incidence figure for vocal effort in hearing-impaired speakers that is more than three times the percentage previously reported. This higher incidence figure may be a result of differences in the hearingimpaired samples, such as their ages or communicative achievement 
levels. It also should be noted, however, that differences existed in the backgrounds of the judges. The speech pathologists who evaluated the young adults at NTID were accustomed to listening to deaf voices. The speech pathologists who judged voices in this study predominately provided services to hearing children and were naive about which of the subjects being rated were hearing-impaired. The possibility exists that the incidence figure reported previously was low because of 1 istener tolerance. Voice quality is a perception and, thus, evaluation of voice can only be accomplished by continual recalibration to that which is considered normal.

Acoustical and Perceptual Differences between Oral/Aural and Total Communication Students

Based upon the results of this study, the voices of hearingimpaired children attending Total Communication programs tend to be perceived as demonstrating greater vocal effort than the voices of students attending Oral/Aural programs. This difference is significant for the vowe $1 / \mathrm{u} /$ and speech. Even though these two groups of hearing-impaired children significantly differ in perceptual measures, physical measures do not reveal significant differences. Vowel spectral noise levels for Total Communication children are not significantly higher, although levels of spectral noise for /a/ tend to be slightly greater.

These results indicate that Oral/Aural children are perceived different from Total Communication children in terms of vocal effort. It is conceivable that children who demonstrate poorer auditory selfmonitoring abilities may rely more heavily upon internal, kinesthetic 
feedback to monitor their speech production, this practice lending itself to increased vocal effort, according to Willemain and Lee (1971). In this study, Total Communication subjects, on the average, demonstrated poorer hearing thresholds by an average of $12 \mathrm{~dB}$. It may be that children with poorer hearing thresholds are more likely to be placed in Total Communication programs than Oral/Aural programs. Children with poorer thresholds also may demonstrate poorer auditory monitoring abilities and, therefore, may rely more heavily upon internal, kinesthetic feedback to monitor speech. If such differences exist in auditory skills between the children in the two different deaf educational programs, it may at least partially explain why Total Communication children are perceived as less normal in vocal effort than Oral/Aural children. 


\section{CHAPTER IV}

\section{SUMMARY AND IMPLICATIONS}

\section{SUMMARY}

Audition is undoubtedly the most efficient means for early acquisition of oral communication skills (Fry, 1978; Ling, 1976). Consequently, the speech of children with limited audition deviates from normal speech in almost all aspects (Calvert and Silverman, 1975). One problem area is voice quality, specifically vocal effort or harshness. Even though abnormal vocal effort is prevalent among hearing-impaired speakers, there is a paucity of information describing the acoustical and perceptual features of this voice quality for hearing-impaired children. Whitehead and Lieberth (1979) explored vocal harshness in hearing-impaired adults and found a significant and systematic increase in the level of inharmonic energy, indexed as spectral noise, as the degree of perceived vocal harshness/tension became more severe. The constraints of the instrument used by Whitehead and Lieberth, however, precluded using children as subjects. To date, no research has been reported that specifically describes vocal effort or harshness in hearing-impaired children. An apparent need, therefore, existed to implement a research design with which hearingimpaired children could comply and that revealed data concerning the perceptual and acoustical features of vocal effort in hearing-impaired children. 
The present study was designed to investigate the perceptual and spectrographic features of vocal effort in the speech of severely to profoundly hearing-impaired children and their normal hearing agemates. Recorded vowel and speech samples were obtained from ten normal hearing children, ten severely to profoundly hearing-impaired children attending Oral/Aural educational programs, and eight severely to profoundly hearing-impaired children attending Total Communication programs. The degree of perceived vocal effort for vowels and speech was evaluated, using a 9-point equal-appearing-interval scale. In order to obtain a physical measurement for vocal effort, a digital wave analyzer was used to produce vowel spectra, and the amount of inharmonic (noise) components in each spectrum was indexed as spectral noise level.

The results indicated: 1) there is a positive and significant correlation of moderate strength between spectral noise levels and perceived degrees of vocal effort for samples of hearing-impaired and normal hearing children; 2) hearing-impaired children tend to demonstrate higher vowel spectral noise levels, although this difference was significant only for the vowel $/ \mathrm{u} /$ and not for the vowe $1 / \mathrm{a} /$; 3) hearing-impaired children are perceived as demonstrating significantly more vocal effort than normal hearing children; 4) Total Communication hearing-impaired students cannot be significantly differentiated from Oral/Aural students in terms of spectral noise levels; and 5) Total Communication students are perceived as demonstrating significantly greater vocal effort than Oral/Aural students for the vowel (u) and for speech. 


\section{IMPLICATIONS}

\section{Clinical Implications}

Results of this investigation indicate that the Hewlett Packard wave analyzer can be successfully utilized to produce vowel spectra from normal hearing and hearing-impaired children's vowel productions. This instrument's advantages over previous wave analyzers include greater inherent accuracy, faster analysis time, and minimal requirements and demands upon subjects for collection of recorded vowel productions. Potential uses for this equipment include diagnostic assessment of vocal effort, monitoring change in clinical management of vocal effort, and perhaps even providing immediate and visual spectrographic feedback during clinical sessions.

Secondly, the perceptual scale for rating vocal effort designed in this investigation served as a useful tool in training judges to listen for features specifically associated with vocal effort in children. The refinement and clinical use of these guidelines, especially for the hearing-impaired population, are recommended. Another assessment strategy which appeared invaluable for the evaluation of vocal effort in hearing-impaired children was the backward playing of recorded speech tapes. This procedure seems particularly important in assessing the voice qualities of hearing-impaired children because of the multiple aberrant articulation and prosody patterns present which may distract the listener.

The significant difference between normal hearing and hearingimpaired children in terms of vocal effort indicates that the hearingimpaired child is working too hard. In an effort to coordinate and 
control the speech mechanism, a skill that hearing individuals seem to learn effortlessly, the speaker with limited audition overworks the muscles used for speech. The problem has long been recognized. Over thirty years ago Bodycomb (1946) observed that severely to profoundly hearing-impaired individuals "speak with such effort that they have little spontaneity." It would seem intervention concerned with retraining or gaining the naturalness of speech and the ability to operate the speech mechanism in a normal, relaxed manner, is crucial. To do so, clinical management must work to eliminate the non-productive strategies used by hearing-impaired speakers to increase kinesthetic feedback during speech by inappropriately tensing muscles. Alternate and more efficient means of receiving information about the appropriateness of speech may include use of visual feedback and maximizing residual hearing.

\section{Research Implications}

Further research is needed to investigate the following variables:

1. Backward playing of speech samples seemed invaluable in this study. Further research might investigate the specific advantages of backward playing, especially for use with the hearing-impaired population. Additionally, the effect of judging speech samples which are characterized by glottal fry and the interpretation of pitch and loudness cues during backward playback need to be more closely examined.

2. Relatively little data are available which investigates the acoustical and perceptual characteristics of children's voices as com- 
pared to the body of data which have been collected to describe adult voices. In order to develop a framework by which to compare and judge abnormally-sounding children, more objective data about normal children are needed. Too often, the only available research concerns adults. One cannot safely assume that norms and the degrees of normal variability for adults are identical for children.

3. Further research is needed to investigate the possible clinical applications of spectral noise level as an acoustical correlate of vocal effort. To date, no investigation has been published which assesses the spectral noise levels of children's vowels pre- and postintervention designed to reduce vocal effort.

4. Hearing-impaired speakers apparently increase muscle tension during phonation. Studies involving electromyography (EMG) could offer additional supportive data about the muscular adjustments the hearing-impaired individual effects during speech.

5. Acoustical correlates other than spectral noise may be predictors of the degree of vocal effort. Further research involving an analysis delineating the predictive power of other possible physical parameters, such as pitch and loudness changes, is warranted.

6. Further investigations comparing the General Radio analog and the Hewlett Packard digital wave analyzers are warranted. Specifically, comparison of larger numbers of vowel spectra would more precisely evaluate if the differences in bandwidth are crucial for clear spectrographic presentation of noise components.

7. The present study and previous studies (Lively and Emanual, 1970; Sansone and Emanual, 1970; Whitehead and Lieberth, 1979) indexed 
the level of vowel spectral noise as the low peak of recorded energy in each 100-Hertz section of vowel spectra. In order to allow comparis on of one vowel's level of spectral noise to another's, the vowels were fed into the wave analyzer at uniform intensities. An alternate, and perhaps more meaningful way of quantifying the level of spectral noise, may be by the derivation of some formula that compares the relative energy of harmonic vs. inharmonic components for each vowel individually. Use of such a formula would eliminate the need to equalize intensity levels prior to spectrographic analysis. 
$\underline{\mathrm{S}} \underline{\mathrm{E}} \underline{\mathrm{L}} \underline{\mathrm{E}} \underline{\mathrm{C}} \underline{\mathrm{T}} \underline{\mathrm{E}} \underline{\mathrm{D}}$

$\underline{B} \underline{\mathrm{I}} \underline{\mathrm{B}} \underline{\mathrm{L}} \underline{\mathrm{I}} \underline{\mathrm{O}} \underline{\mathrm{G}} \underline{\mathrm{R}} \underline{\mathrm{A}} \underline{\mathrm{P}} \underline{\mathrm{H}} \underline{\mathrm{Y}}$ 


\section{SELECTED BIBLIOGRAPHY}

ANGELOCCI, A., KOPP, G., and HOLBROOK, A., The vowel formants of deaf and normal hearing 11 to 14 year old boys. J. Speech Hearing Dis., 29, 156-70 (1964).

BODYCOMB, M., The speech of the deaf and the normal speaker. Volta Review, 48, 637-38 (1946).

BOONE, D., Modification of the voices of deaf children. Volta Review, $68,686-94$ (1966).

, The Voice and Voice Therapy. Englewood Cliffs, N.J.:

Prentice-Ha11, Inc. (1977).

CACCAMISE, F., and DRURY, A., A review of current terminology in education of the deaf. Deaf American, September, 7-10 (1976).

CALVERT, D., and SILVERMAN, S., Speech and Deafness. Washington, D.C.: A. G. Bell Association for the Deaf (1975).

COLTON, R., and COORER, H., Perceived nasality in the speech of the deaf. J. Speech Hearing Res., 11, 553-59 (1968).

FLETCHER, S., and DALY, D., Nasalance in utterances of hearingimpaired speakers. J. Comm. Dis., 9, 63-73 (1976).

FORNER, L., and HIXON, T., Respiratory kinematics in profoundly hearing-impaired speakers. J. Speech Hearing Res., 20, 373-408 (1977).

FRY, D., The role and primacy of the auditory channel in speech and language development. In M. Ross and T. Giolas (Eds.), Auditory Management of Hearing-Impaired Children. Baltimore, Md.: University Park (1978).

GILBERT, H., and CAMPBELL, A., Simultaneous oral and nasal airflow during stop consonant production by hearing-impaired speakers. Folia Phoniat., 27, 423-37 (1978).

GOODMAN, A., Reference zero levels for pure-tone audiometers. ASHA, 7, 262-63 (1965).

GUILFORD, J., Fundamental Statistics in Psychology and Education. New York: McGraw-Hill Book Co., Inc. (1956).

HOOD, R., and DIXON, R., Physical characteristics of speech rhythm of 
deaf and normal hearing speakers. J. Comm. Dis., 2, 20-28 (1969).

HORII, Y., Vocal shimer in sustained phonation. J. Speech Hearing Res., 23, 202-9 (1980).

HUDGINS, C., and NUMBERS, G., An investigation of the intelligibility of the speech of the deaf. Genetic Psychology Monograms, 25, 289-392 (1942).

ISSHIKI, N., YANAGIHARA, N., and MORIMOTO, M., Approach to the objective diagnosis of hoarseness. Folia Phoniat., 18, 393-402 (1966).

KATZ, J., Clinical Audiology. In J. Katz (Ed.), Handbook of Clinical Audiology. Baltimore, Md.: Williams and Wilkins (1978).

LING, D., Speech and the Hearing-Impaired Child: Theory and Practice. Washington, D.C.: A. G. Bell Association for the Deaf (1976).

LIVELY, M., and EMANUAL, F., Spectral noise levels and roughness severity ratings for normal and simulated rough vowels produced by adult females. J. Speech Hearing Res., 13, 503-17 (1970).

MARKIDES, A., The speech of deaf and partially hearing children with special reference to factors affecting intelligibility. $\mathrm{Br}$. J. Disord. Comm. , 5, 126-40 (1970).

MARTONY, J., On the correction of the voice pitch level for severely hard of hearing subjects. American Annals for the Deaf, 113, 195-202 (1968).

MASON, M., and BRIGHT, M., Tempo in rhythmic speech education. American Anna 1s for the Deaf, 82, 385-401 (1937).

MCGARR, N., and OSBERGER, M., Pitch deviancy and intelligibility of deaf speech. J. Comn. Dis., 11, 237-47 (1978).

MICHEL, J., and WENDAHL, R., Correlates of voice production. In L. Travis (Ed.), Handbook of Speech Pathology and Audiology. New York: Apple-Century Crofts (1971).

MONSEN, R., Acoustic qualities of phonation in young deaf children. J. Speech Hearing Res., 22, 270-88 (1979).

MONSEN, R., ENGEBRETSON, A., and VEMULA, N., Some effects of deafness on the generation of voice. J.Acoust. Soc. Amer., 66, 1680-90 (1979).

NICKERSON, R., Characteristics of the speech of deaf persons. Volta Review, 77, 342-61 (1975). 
NICOLOSI, L., HARRYMAN, E., and KRESHECK, J., Terminology of Communication Disorders. Baltimore, Md.: Williams and Wilkins Co. (1978).

NIE, N., HULL, C., JENKINS, J ., STE INBREANER, K., and BENT, D., Statistical Package for the Social Sciences. New York: McGrawHil1 Book Co. (1975).

NOBER, E., Articulation of the deaf. Exceptional Child, 33, 611-21 (1967).

PARKHURST, B., and LEVITT, H., The effects of selected prosodic errors on the intelligibility of deaf speech. J. Comm. Dis., 11, 249-56 (1978).

PENN, J., Voice and speech patterns of the hard of hearing. Acta Otolaryngologica, S. 24, 9-67 (1955).

PERKINS, W., Optimal vocal functioning. J. Calif. Speech and Hearing Association, February, 48-51 (1968).

SANSONE, F., and EMANUAL, F., Spectral noise levels and roughness ratings for normal and simulated rough vowels produced by adult males. J. Speech Hearing Res., 13, 489-502 (1970).

SHERMAN, D., The merits of backward playing of connected speech in the scaling of voice quality disorders. J. Speech Hearing Dis., 19 , 312-21 (1954).

SHERMAN, D., and LINKE, E., The influence of certain vowel types on degree of harsh voice quality. J. Speech Hearing Dis., 17 , 401-8 (1952).

SPECTOR, P., SUBTELNY, J., WHITEHEAD, R., and WIRZ, S., Description and evaluation of a training program to reduce vocal tension in adult deaf speakers. Volta Review, 81, 81-90 (1979).

STEVENS, K., NICKERSON, R., BOOTHROYD, A., and ROLLINS, A. , Assessment of nasalization in the speech of deaf children. J. Speech Hearing Res., 19, 393-414 (1976).

WHITEHEAD, R., and LIEBERTH, A., Spectrographic and perceptual features of vocal tension/harshness in hearing-impaired adults. J. Comm. Dis., 12, 83-92 (1979).

WILLEMAIN, T., and LEE, F., Tactile pitch feedback for deaf speakers. Volta Review, 73, 541-54 (1971).

WIRZ, S., SUBTELNY, J., and WHITEHEAD, R., Perceptual and spectrographic study of tense voice in normal and deaf subjects. Folia Phoniat., 33, 23-36 (1981). 
ZEMLIN, W., Speech and Hearing Science: Anatomy and Physiology.

Englewood Cliffs, N.J.: Prentice-Hal1 (1968). 
A $\underline{P} \underline{P} \underline{\mathrm{E}} \underline{\mathrm{N}} \underline{\mathrm{D}} \underline{\mathrm{I}} \underline{\mathrm{C}} \underline{\mathrm{E}} \underline{\mathrm{S}}$ 
APPENDIX A

PARENT PERMISSION SLIP

January 5, 1982

Dear Parent or Guardian,

I am a speech pathology student at Portland State University and would like your child to help me with a research project. The purpose of my study is to find a more helpful way to evaluate the voices of hearingimpaired children.

If you and your child agree to help me, your child will meet with me on a mobile van at school for a few minutes. Your child's teacher will accompany us. The van provides a quiet room, like the rooms used for testing hearing. In the van, your son or daughter will say some sounds and name pictures while I tape record his or her voice. This will only take about 5-10 minutes and your child's help will be greatly appreciated.

I would also like to know a little more about your child's hearing loss. I would appreciate you answering the questions found below concerning your child's hearing impairment. Additionally, you will find attached a Release of Information Form. Your signature on this form allows me to look at your child's audiogram. All information and names will be kept confidential.

Please feel free to contact your child's teacher if you have any questions. You can also reach me at Portland State University Speech and Hearing Program (229-3533). Please return the following slip tomorrow, or as soon as possible, to your child's teacher. I sincerely appreciate your cooperation in my study.

Thank you

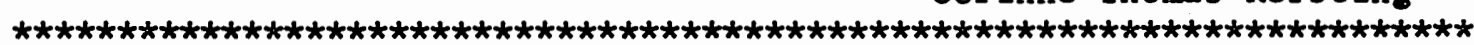

I,

this study. hereby permit my son/daughter to participate in

I, agree to be in this study.

How old was your child when his hearing loss was diagnosed?

Did he hear all right at any time before then?

What caused your child's hearing impairment? meningitis congenital rheubella other (describe) unknown 
APPENDIX B

PARENT PERMISSION SLIP

January 5,1982

Dear Parent or Guardian,

I am a speech pathology student at Portland State University and would like you to help me with a research project. The purpose of my study is to find a more helpful way to evaluate voices of deaf and normal children.

If you and your child agree to help me, your child will meet with me on a mobile van at school for a few minutes. The van provides a quiet room that can be used for testing hearing. I will screen your child's hearing by seeing how well he hears tones. Then your son or daughter will say some sounds and name some pictures while I tape record his or her voice. This will only take 5-10 minutes and your child's help will be greatly appreciated. All information and names will be kept confidential.

Please feel free to contact me at Portland State University Speech and Hearing Program (229-3533) if you have any questions. I sincerely appreciate your cooperation in my study.

Thank you

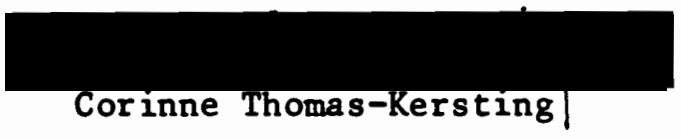

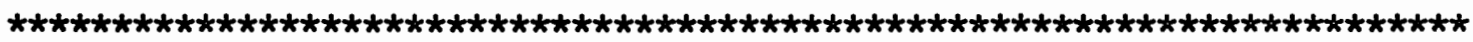

I, hereby permit my son/daughter to participate in this study.

I, agree to be in this study. 


\section{APPENDIX C}

\section{INSTRUCTIONS FOR ELICITING /ba/ AND/bu/}

"I want you to say /ba/. Say /b a/." (Experimenter models /ba/, produced with normal duration. Experimenter listens for and shapes the target vowel production. If necessary, the researcher will elicit the production of these consonant-vowel syllables by showing the child pictures that are designed to stimulate the production of the sound, i.e., pictures of a sheep and a ghost.)

"Good. Now I want you to say /ba a/...." (Experimenter sustains the vowel sound for at least one second, pairing the sustained vowel with the horizontal movement of her hand, left to right. Experimenter repeats this visual cueing during the subject's trail, giving feedback on appropriate duration.)

"Great. Now I want you to say that into the microphone and make this needle stay in one place, like this." (Experimenter demonstrates production of /baa/. . at constant intensity by monitoring the V.U. meter's needle.)

"Now, you do it. Make the needle stay in one place." (Experimenter allows a few trials until she is satisfied that the subject understands the nature of the task.)

"I am going to record you this time." (Experimenter turns on recording device.) "Say /ba $a /$. . ." (Experimenter continues until first correct production of sufficient duration and uniform 
Appendix C (Cont.)

intensity is obtained. Experimenter then turns off recorder and repeats steps with the syllable /bu/.) 


\section{APPENDIX D}

SELECTED EXAMPLES OF VOWEL SPECTRA PRODUCED BY THE HEWLETT PACKARD WAVE ANALYZER 
EXAMPLE 1

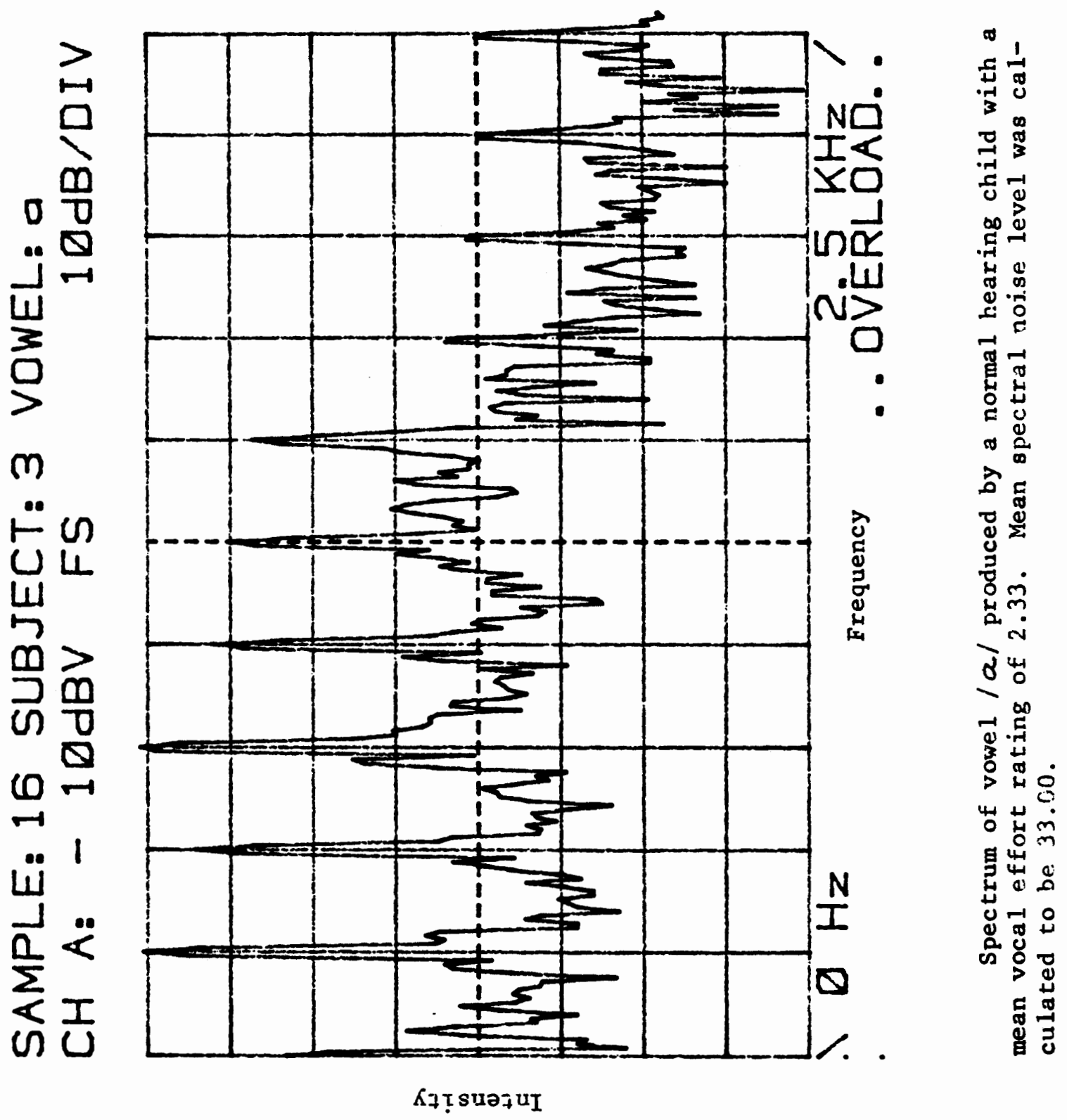


EXAMPLE 2

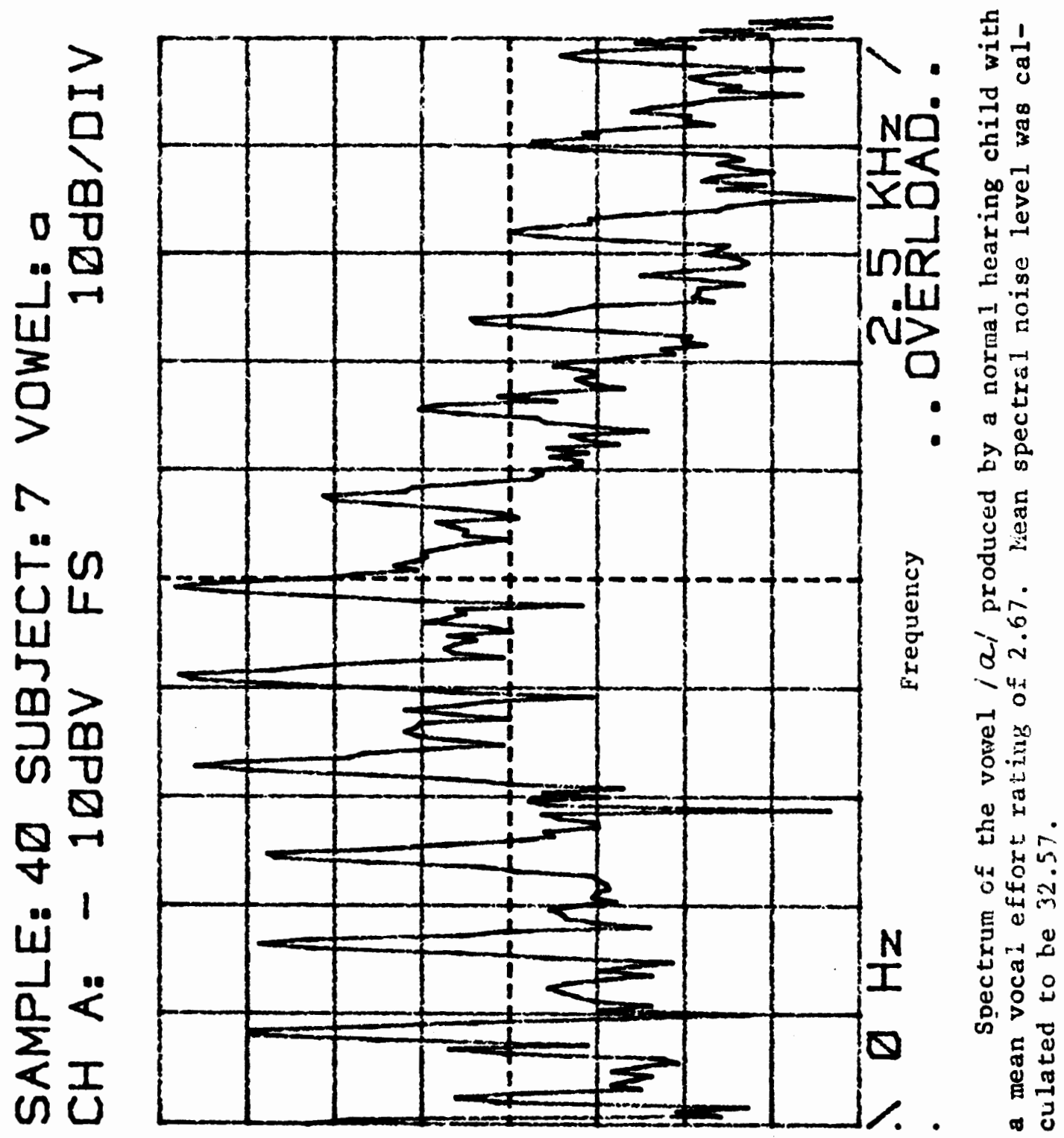

Кำงน⿰习习ิ 
EXAMPLE 3

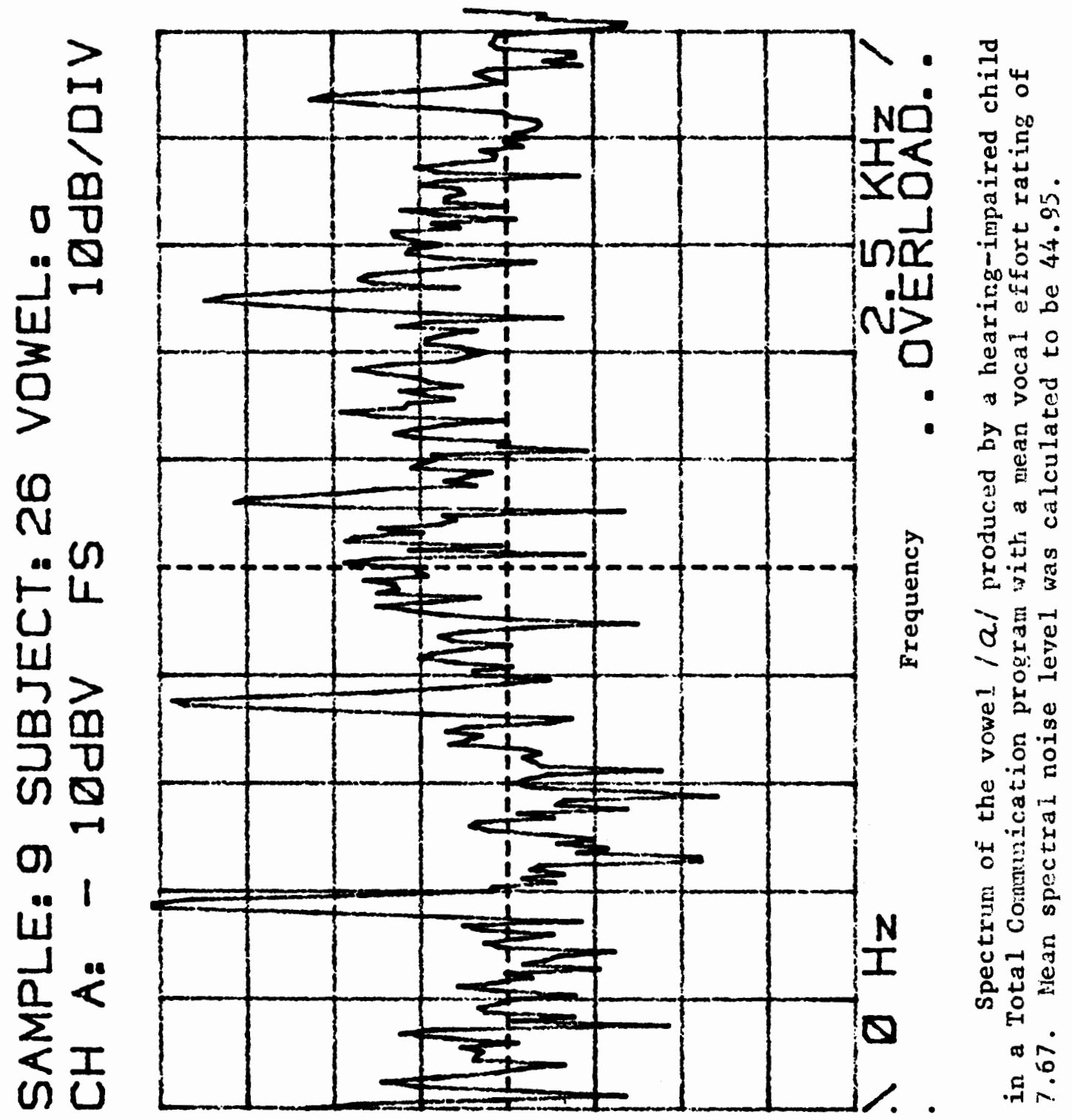

К‡TsLiəzUI 
EXAMPLE 4

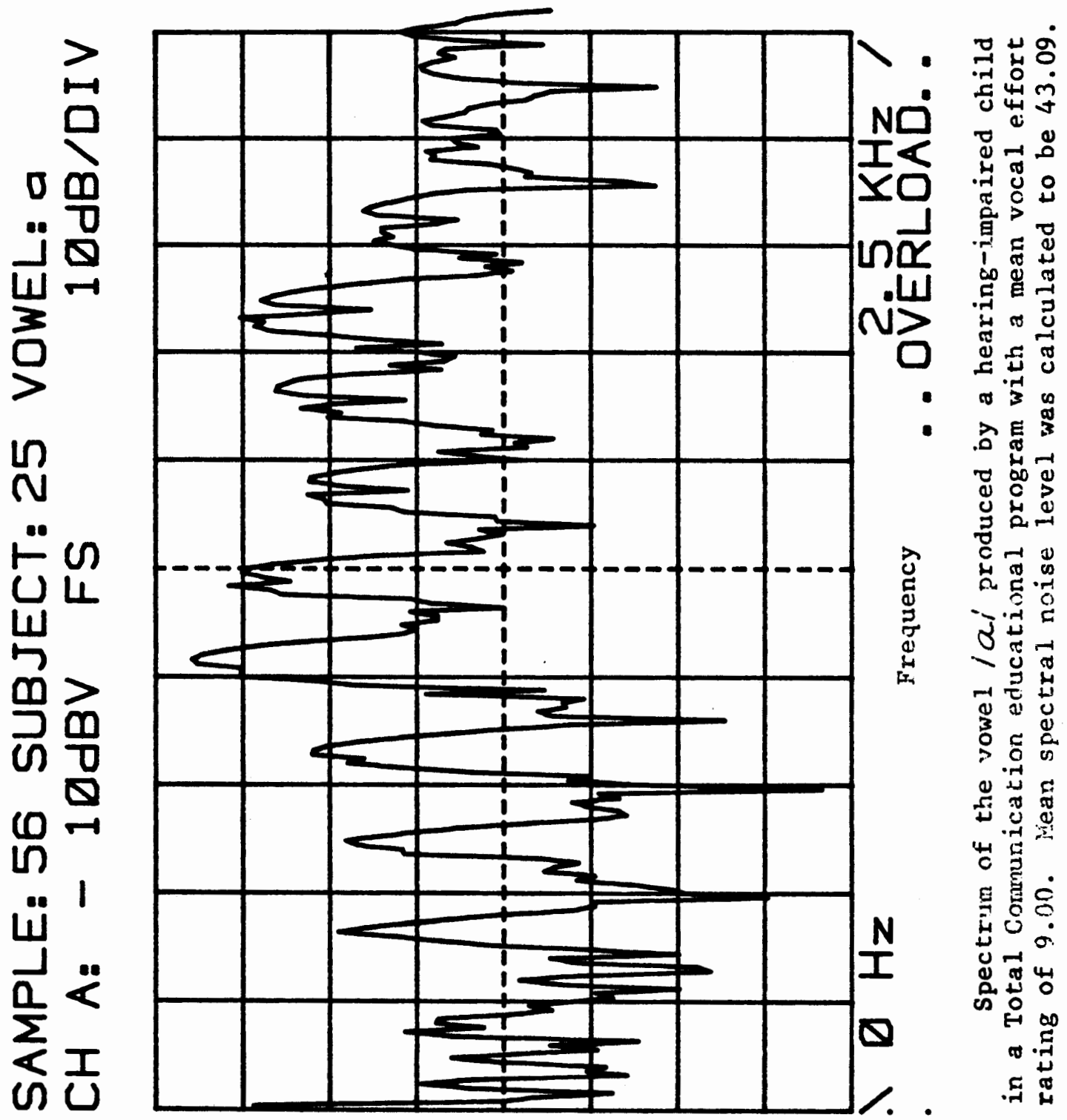

Кวโุ sนวุนI 
EXAMPLE 5

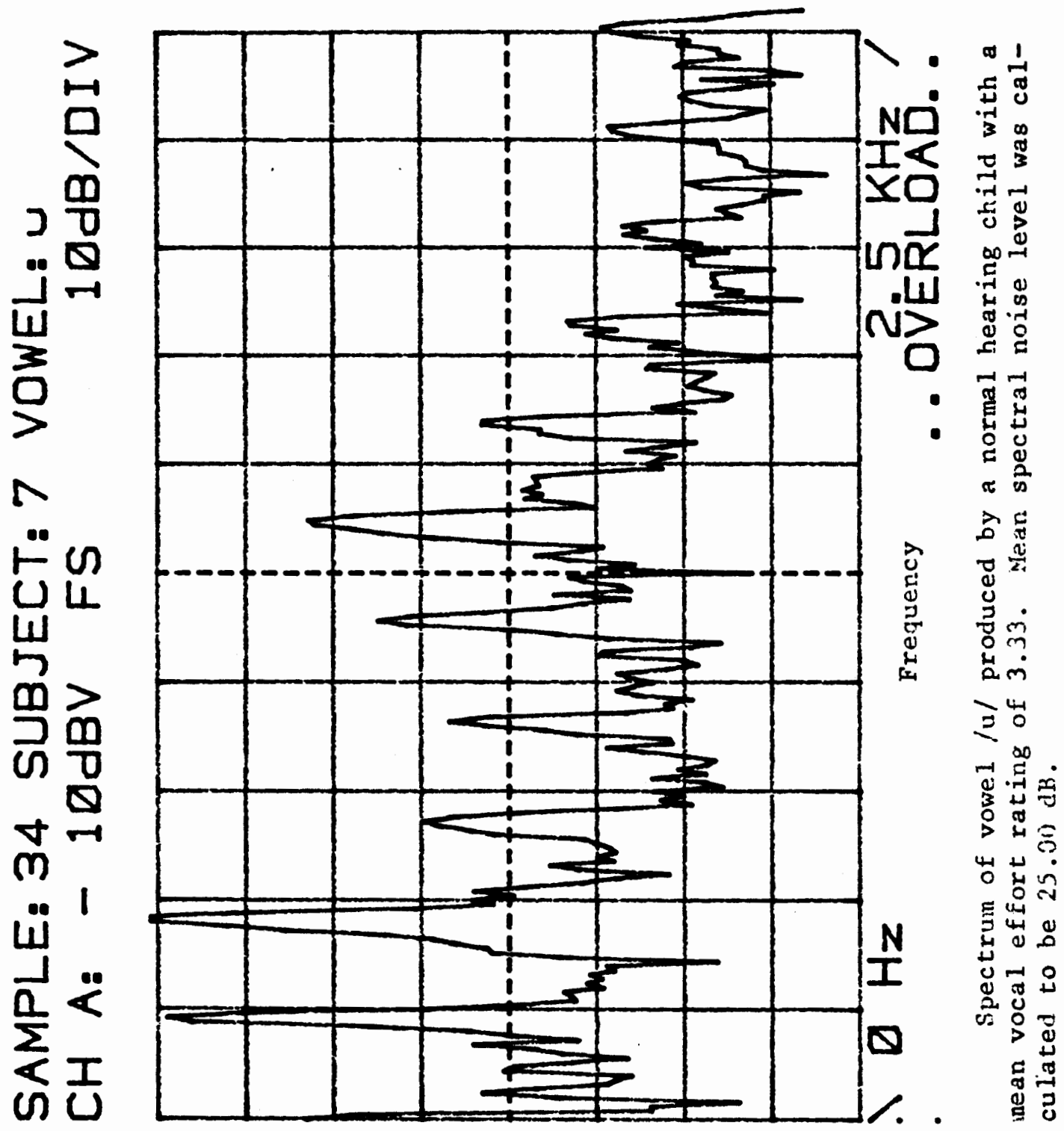

ห7т suazuI 
EXAMPLE 6

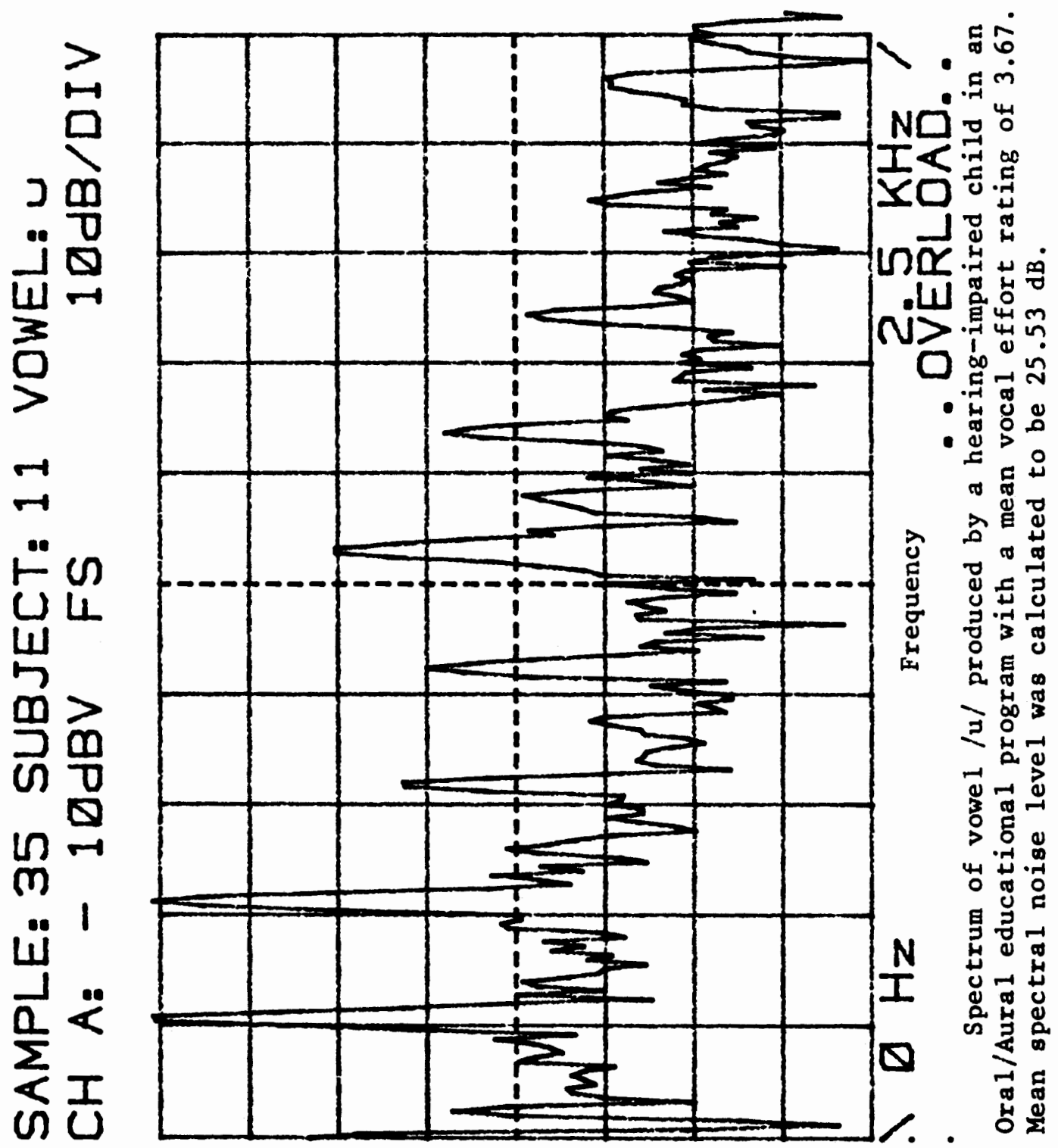

Кำ8นวجนI 
EXAMPLE 7

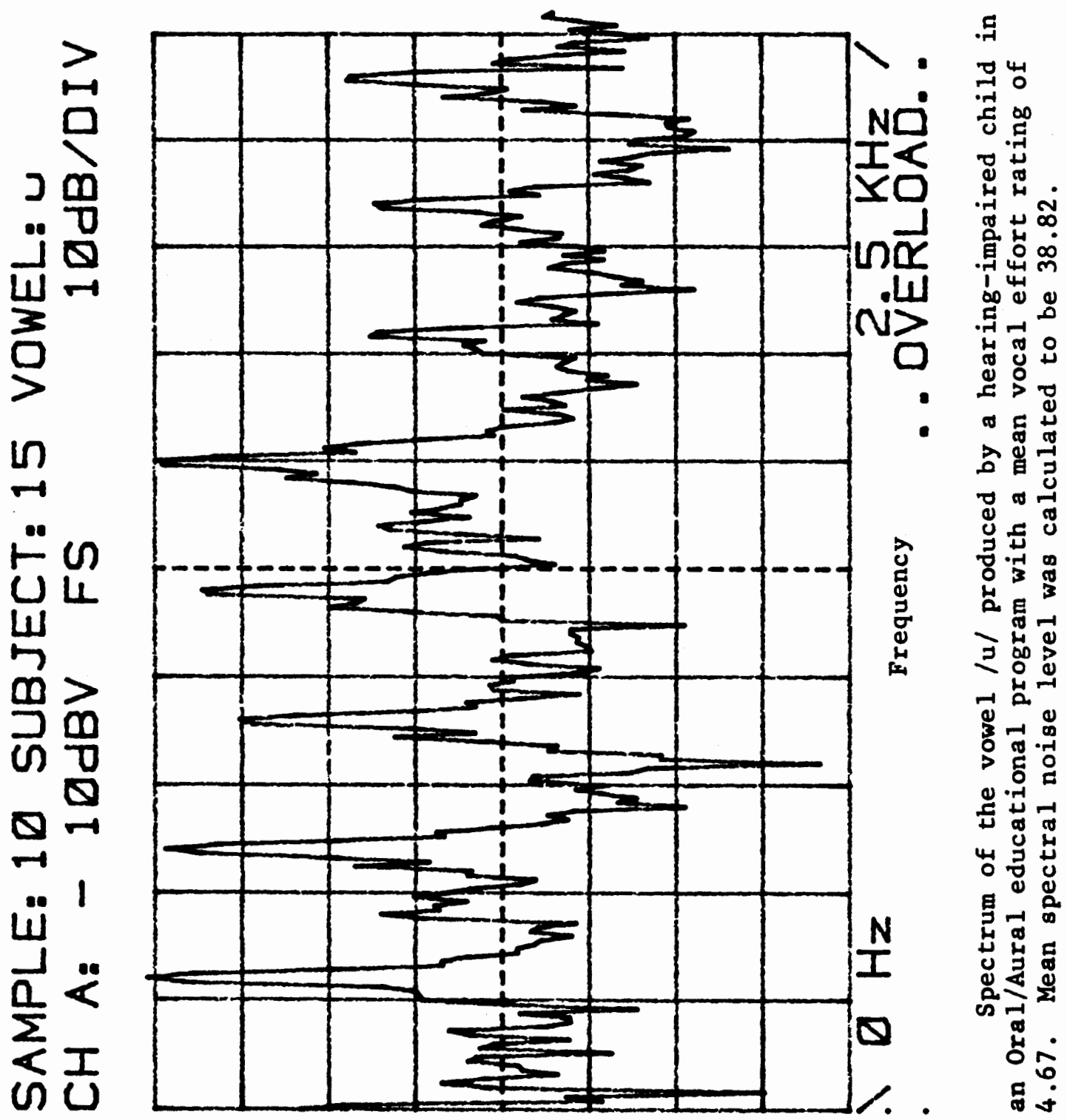

КำงนวานI 
EXAMPLE 8

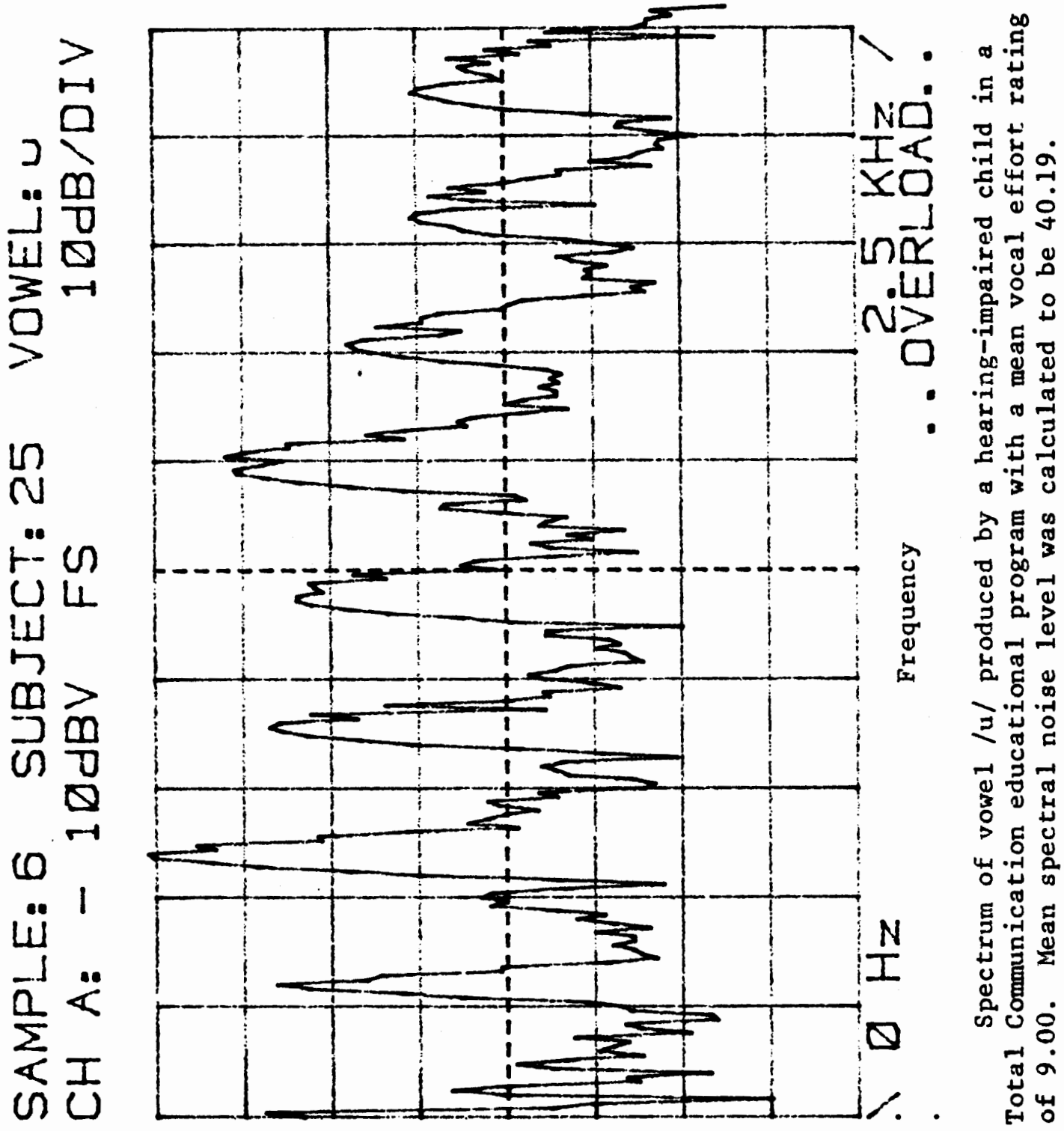

Kวโุsuə7uI 
INSTRUCTIONS TO JUDGES-VOCAL EFFORT RATING

PART I: TRAINING SESSION FOR VOWELS

The following was read to the judges:

I wart to find out the perceived degree of vocal effort for some speech samples and I want you to help. First, you are going to listen to some children producing vowels. The vowel samples you are about to hear are similar to the ones you will be asked to judge for vocal effort. Just listen and become accustomed to the way these recorded vowels sound. The recorded vowel samples are short, about one second long each. $/ \overline{\mathrm{P}}$ lay training tape with twenty-seven vowel samples. Provide no repetitions. $\overline{-}$

For our vocal effort judgements, we are going to use a 9-point equal-appearing-interval scale. "One" means normal, easy phonation. "Nine" relates to the greatest vocal effort. Look at the handout labeled "Guidelines for Perceptual Judgement: Vocal Effort" /Äppendix HT. These guidelines for using the 9-point scale were developed by myself and another listener. We started independently listening to the vowel samples and made our own judgements prior to discussing what voice features we were attending to. We were very encouraged in terms of the amount of agreement we achieved, even though it seemed many of our judgements were made on an intuitive level. We began to attend to the features that were influencing our perceptions of vocal effort and developed these general rules. These guidelines are designed to 
facilitate listeners in tuning in to the features which seem indicative of vocal effort.

As I stated before, on the 9-point vocal effort scale, "1" means normal phonation and "g" relates to the most severe degree of vocal effort. Look at the primary factors listed on the handout. Each scaled value " 1 " through " 9 " is associated with primary descriptors. Speakers may receive a rating of "1" (normal, mellow) or "9" (strangled or closed) or any whole number in between ("2," "3," "4, "5," "6," "7," "8"). You will notice that some of the descriptors that are assigned to the same value may not be synonymous. For example, "thin" or "strained" is associated with the scaled value "6."

For our purposes, vocal effort is defined as the "perceived degree of labor" which may be associated with pitch and intensity problems, overadduction of the vocal folds, and/or aberrant resonance characteristics resulting from tongue retraction, pharyngeal constriction INicolosi, Harryman, and Kresheck, 1978 $\mathrm{T}$ and/or oral cavity tension. We are dealing with the whole vocal mechanism-generation and resonation of the tone. The scale from " 1 " through "g" represents a continum of effort and the associated descriptions represent the different manifestations of that effort or increasing tension. You can generalize that the scaled values " 1 " through " 3 " relate to the normal speaker, "4" through "6" to the speaker exhibiting a moderate degree of effort, and "7" through " 9 " to the speaker whose phonations are characterized by severe effort.

Now, look at the secondary factors listed on the handout. They are "micro-changes in pitch and loudness," "macro-changes in pitch and 
loudness," and "noise." I will demonstrate to you what some of these sound like and what they are physiologically associated with. For example, "micro-changes" in pitch and loudness sound like the "uneven" or "irregular" generation of tone at the level of the larynx. "Noise" may be the result of inappropriately tense articulators, such as the tongue or lips, interfering with the flow of air and creating a "friction-type" or "rushing noise." Inappropriate vocal effort of the articulators during speech also can result in exaggerated jaw movement. When this happens, the mouth is opened inappropriately wide and produces another type of "noise," sounding like a "spread of frequencies."

Read the guidelines at the bottom of the handout which describes how to evaluate vocal effort with this 9-point scale. [Read together. $\bar{T}$

Now, I will play a tape for you of voices which exemplify each rating value. I $\mathrm{P}$ lay training tape which demonstrates the spread of effort severity ratings from " 1 " through "9."7

Now, we are going to spend some time listening to some vowels on a training tape and practice using the rating scale. I will prepare you by telling you what number of vowel sample is about to be played. Then, you will hear the vowel presented twice in a row. The second presentation of the vowel will follow the first within five to ten seconds. We will stop and discuss our ratings, after judging each vowel sample, for about the first ten vowels. Then we will stop and compare after completing groups of five to fifteen vowels. Are there any questions? ITraining on vowels continues until satisfactory inter- and intra-judge reliability is achieved. 7 


\section{APPENDIX F \\ INSTRUCTIONS TO JUDGES - VOCAL EFFORT RATING \\ PART II: VOWEL JUDGEMENTS}

The following was read to the judges:

You have learned to use the perceptual rating scale to judge vocal effort. Now we are going to hear a total of sixty-six different vowel samples and you will make individual judgements. Use the 9point scale for vocal effort that you have been trained with. Feel free to refer back to the handout on "Perceptual Judgement of Vocal Effort" as often as you would like during this rating session.

Remember, you will, hear each vowel sample only twice. Individually choose the scaled value which best describes the vowel production. Write that rating next to the appropriate sample number on the response form in front of you. Be sure to leave no blanks. We will start with number one and proceed through number thirty-three. We will then take a short break. Please don't discuss any of the vowels you have just judged during your break. After the break, we will individually judge vowel samples thirty-four through sixty-six. Are there any questions? 
APPENDIX G

\section{INSTRUCTIONS TO JUDGES-VOCAL EFFORT \\ PART III: TRAINING AND JUDGEMENT \\ OF SPEECH SAMPLES}

The following was read to the judges:

Now that you are experts in judging vocal effort in vowels, I would like you to apply your skills to samples of single-word responses. We are going to listen to some children naming pictures. These speech samples, consisting of twenty picture-namings each, will be unintelligible. That is because you will be hearing the recorded tape being run backwards. Don't worry about not being able to understand. I want you to pay attention to the voice quality only, and ignore the articulation and rhythm. You will find it helpful to focus upon the vowel portions of the speech samples. Vowels are a resonance phenomenon and voice quality is most apparent during production of vowels. Attend to the voice quality in terms of vocal effort or strain.

First I am going to play a training tape of speech samples. Just 1 isten and become accustomed to the way backward recorded speech sounds. These speech samples you are about to hear are similar to the ones you will be asked to judge for vocal effort. L/ 1 lay training tape with twelve speech samples. Provide no repetitions. $T$

Now we are going to listen to the same training tape, one speech sample at a time. I will stop the tape recorder after each sample and 
I would like you to share how you would rate the speech sample, using the 1 through 9 vocal effort scale. Also, you may briefly discuss what led you to reach that conclusion. Speech is a multidimensional event and each of you may attend to different aspects of each child's speech. You may find it particularly helpful to share your strategies for evaluating vocal effort for these speech samples. Are there any questions before we proceed with listening to these tapes? I/ 1 lay training tape of speech samples, pausing for discussion after each sample. $T$

Now, I would like you to apply your skill for evaluating vocal effort for speech and individually judge thirty-three speech samples. Again, feel free to refer back to the "Perceptual Judgement" handout during this rating session.

You will hear each speech sample only once. Individually choose a value which best describes the vocal effort in each speech sample and write that number on your response sheet next to the appropriate sample number. Be sure to leave no blanks. We will start with sample number one and proceed through sample number seventeen, and then take a short break. Please don't discuss any of the speech samples you have judged during your break. After the break, you will individually rate speech samples number eighteen through thirty-three. 


\section{APPENDIX H}

GUIDELIMES FOR PERCEPTUAL JUDGEMEIT: VOCAL EFTORT

WHAT TO LISTEN FOR:

\section{Primery Pactore:}

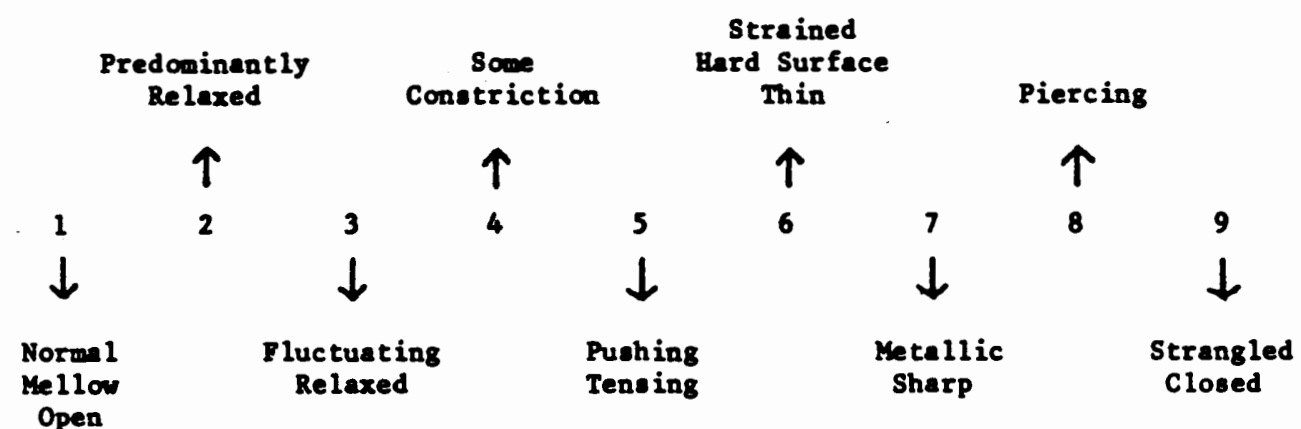

Secondary Factors:

Micro-changes in pitch and loudness: uneven, warbled, rough

Macro-changes in pitch and loudness: exaggerated inflection, uncontrolled Variation

Noise: friction, aperiodicity, spread of frequencies within a sound, rushing noise

BON TO JUDGE:

Supplement what you hear with kinesthetic/proprioceptive feedback about wuscle tension; ohadow the physiological posture.

The effort rating will predominantly be a judgement of which primary factor best describes the voice ample. The presence of one or more secondary factors, however, my cause the severity judgement to increase in value one or two points.

Branching atrategies for achieving focus:

If you have difficulty deciding between two adjacent values when assigning a rating, choos the number associated with an upward arrow $(\uparrow)$.

If you have difficulty deciding between two values associated with upward arrows ( $\uparrow$ ), choose the value between these two ratinge associated with a downard arrow $(\mathfrak{l})$. 